\title{
Improving the Dissolution Rate of Anticancer Drug Dabrafenib
}

Sunil K. Rai, ${ }^{\dagger}$ Anilkumar Gunnam, ${ }^{\ddagger}$ M. K. Chaitanya Mannava $\$$ and Ashwini K. Nangia*广†

†Division of Organic Chemistry, CSIR - National Chemical Laboratory, Dr. Homi Bhabha Road, Pune 411008, India

\$School of Chemistry, University of Hyderabad, Prof. C. R. Rao Road, Gachibowli, Central University P.O., Hyderabad 500 046, India

Email: *Email: ashwini.nangia@gmail.com, ak.nangia@ncl.res.in

\section{Table of Contents}

1. Calculated pKa values of Dabrafenib and coformers

Page S1

2. Single crystal X-ray Crystallography

Page S2-S7

3. Powder X-ray Diffraction Analysis

Page S8-S19

4. Differential Scanning Calorimetry (DSC) data

Page S20-S25

5. Thermal Gravimetric Analysis (TGA) data

Page S26-S30

6. HPLC chromatogram of DBF

Page S31 
1. Calculated pKa values of Dabrafenib and coformers

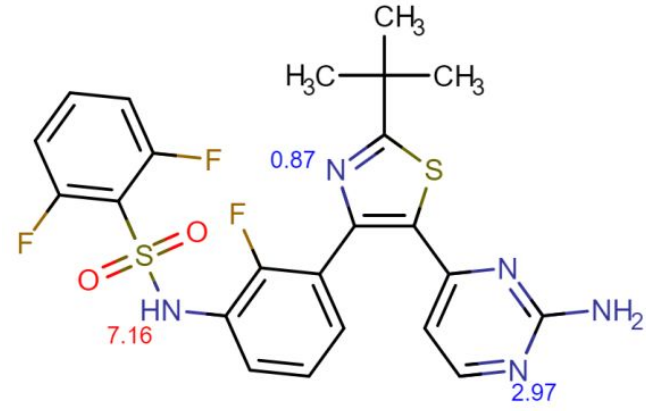

DBF<smiles></smiles>

MS<smiles>O=C1NS(=O)(=O)c2ccccc21</smiles>

SACH

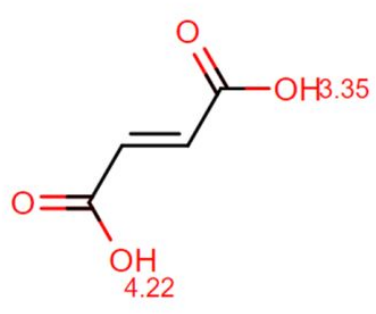

FA<smiles>CCCCCCC(=O)O</smiles>

SA<smiles>O=C(O)CCCCC(=O)O</smiles>

ADA<smiles>CC(C)[18OH]</smiles>

isoPA<smiles>CCCNC(C)CC</smiles>

secBA<smiles>CC(C)CNC(=O)O</smiles>

isoBA<smiles></smiles>

cycloHA

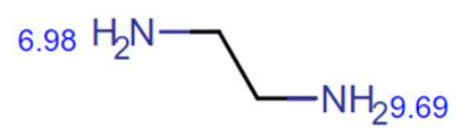

EN

Scheme S1. Chemical structures and calculated pKa values (source: ChemAxon) of DBF and coformers. 
2. Single crystal X-ray Crystallography details

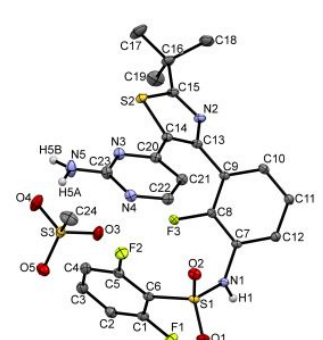

(a)

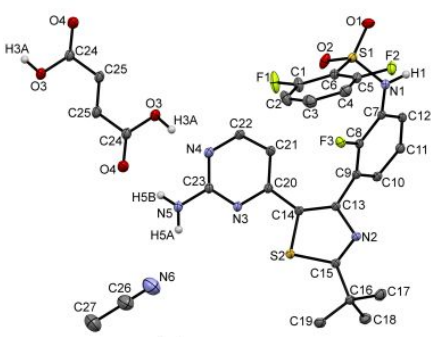

(c)

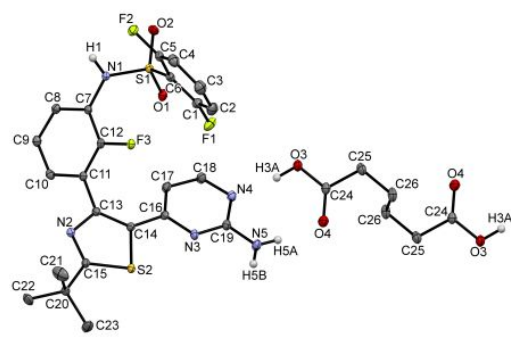

(e)

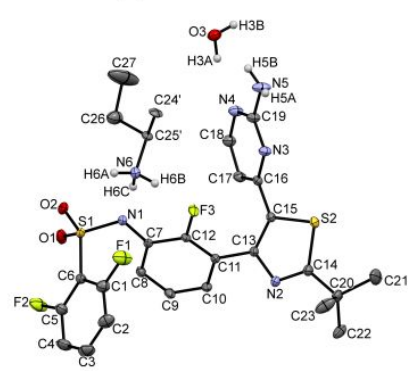

(g)

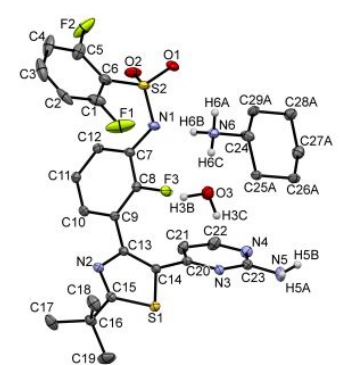

(i)

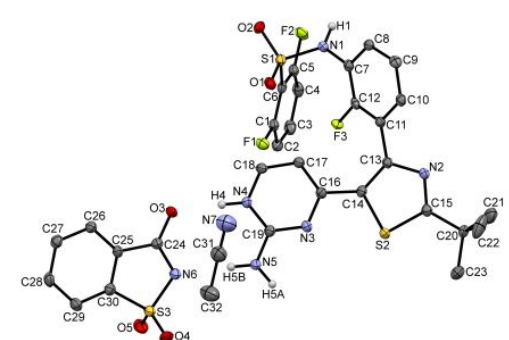

(b)

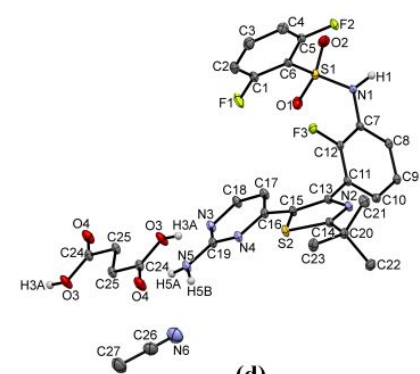

(d)

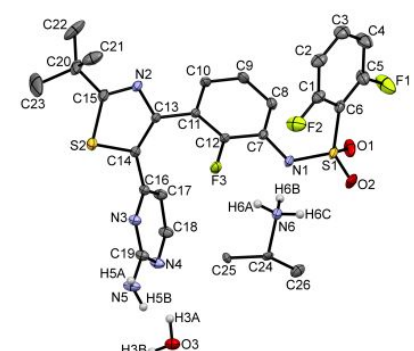

(f)

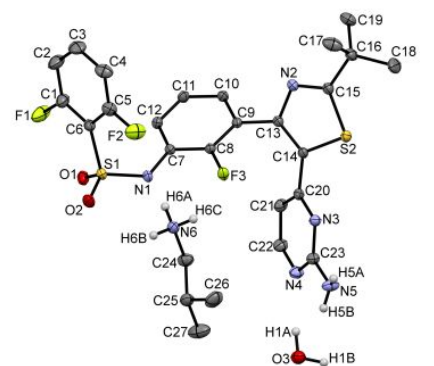

(h)

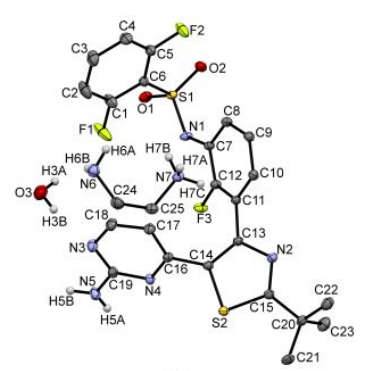

(j)

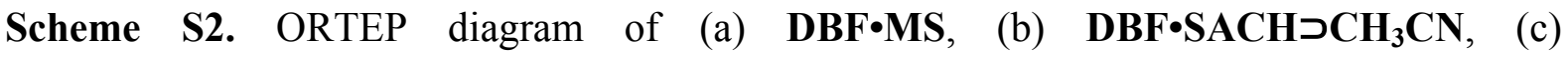

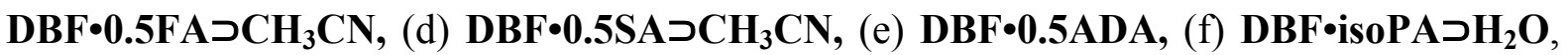

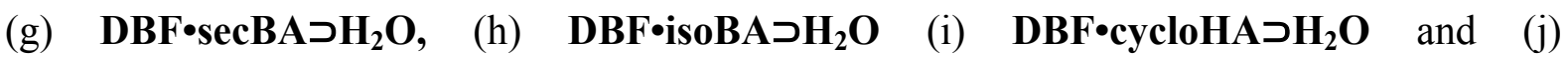
DBF•EN $\supset \mathrm{H}_{2} \mathbf{O}$. The thermal ellipsoids are drawn at 50\% probability level and hydrogen atoms connected to carbon are omitted for the clarity. 
Table S1.Geometrical parameters of intra- and intermolecular hydrogen bonds in salts and cocrystals of Dabrafenib.

\begin{tabular}{|c|c|c|c|c|}
\hline $\mathbf{D}-\mathbf{H} \cdots \mathbf{A}$ & $\begin{array}{l}\mathbf{H} \cdots \mathbf{A} \\
(\AA)\end{array}$ & $\mathbf{D} \cdots \mathbf{A}(\AA)$ & $\begin{array}{l}D-H \cdots A \\
(\mathrm{deg})\end{array}$ & symmetry code \\
\hline & & $\mathrm{DBF} \cdot \mathrm{MS}$ & & \\
\hline $\mathrm{N} 1-\mathrm{H} 1 \cdots \mathrm{N} 2$ & 2.18 & $2.9785(1)$ & 157 & $1-x,-y, 1-z$ \\
\hline N5-H5A $\cdots \mathrm{O} 4$ & 1.99 & $2.9229(1)$ & 170 & $\mathrm{x}, \mathrm{y}, \mathrm{z}$ \\
\hline N5-H5B $\cdots \mathrm{O} 5$ & 1.96 & $2.8177(1)$ & 163 & $-\mathrm{x},-1 / 2+\mathrm{y}, 1 / 2-\mathrm{z}$ \\
\hline N4-H6‥O3 & 1.84 & $2.6728(1)$ & 177 & $\mathrm{x}, \mathrm{y}, \mathrm{z}$ \\
\hline $\mathrm{C} 4-\mathrm{H} 4 \cdots \mathrm{O} 4$ & 2.39 & $3.3326(1)$ & 174 & $-\mathrm{x},-1 / 2+\mathrm{y}, 1 / 2-\mathrm{z}$ \\
\hline $\mathrm{C} 10-\mathrm{H} 10 \cdots \mathrm{O} 1$ & 2.52 & $3.4071(1)$ & 156 & $\mathrm{x}, 1 / 2-\mathrm{y}, 1 / 2+\mathrm{z}$ \\
\hline $\mathrm{C} 12-\mathrm{H} 12 \cdots \mathrm{O} 3$ & 2.40 & $3.0278(1)$ & 123 & $1-x, 1-y, 1-z$ \\
\hline \multirow[t]{2}{*}{$\mathrm{C} 17-\mathrm{H} 17 \mathrm{~A} \cdots \mathrm{O} 5$} & 2.54 & $3.4603(1)$ & 157 & $\mathrm{x}, 1 / 2-\mathrm{y}, 1 / 2+\mathrm{z}$ \\
\hline & & $\mathrm{DBF} \bullet \mathrm{SACH} \supset \mathrm{CH}_{3} \mathrm{CN}$ & & \\
\hline $\mathrm{N} 1-\mathrm{H} 1 \cdots \mathrm{N} 2$ & 2.15 & $3.0198(1)$ & 163 & $1-x, 1-y,-z$ \\
\hline $\mathrm{N} 4-\mathrm{H} 4 \cdots \mathrm{O} 3$ & 1.81 & $2.7122(1)$ & 177 & $\mathrm{x}, 1 / 2-\mathrm{y}, 1 / 2+\mathrm{z}$ \\
\hline N5-H5A $\cdots$ O4 & 1.95 & $2.9046(1)$ & 170 & $-\mathrm{x}, 1 / 2+\mathrm{y}, 1 / 2-\mathrm{z}$ \\
\hline N5-H5B $\cdots$ N6 & 2.01 & $2.8948(1)$ & 173 & $\mathrm{x}, 1 / 2-\mathrm{y}, 1 / 2+\mathrm{z}$ \\
\hline $\mathrm{C} 4-\mathrm{H} 4 \mathrm{~A} \cdots \mathrm{O} 1$ & 2.43 & $3.3697(1)$ & 172 & $\mathrm{x}, 1 / 2-\mathrm{y},-1 / 2+\mathrm{z}$ \\
\hline $\mathrm{C} 8-\mathrm{H} 8 \cdots \mathrm{O} 3$ & 2.34 & $3.1932(1)$ & 149 & $1-\mathrm{x}, 1 / 2+\mathrm{y}, 1 / 2-\mathrm{z}$ \\
\hline \multirow[t]{2}{*}{$\mathrm{C} 32-\mathrm{H} 32 \mathrm{~A} \cdots \mathrm{O} 5$} & 2.57 & $3.4691(1)$ & 153 & $\mathrm{x}, 1 / 2-\mathrm{y}, 1 / 2+\mathrm{z}$ \\
\hline & & $\mathrm{DBF} 0.5 \mathrm{FA} \supset \mathrm{CH}_{3} \mathrm{CN}$ & & \\
\hline $\mathrm{N} 1-\mathrm{H} 1 \cdots \mathrm{N} 2$ & 2.17 & $2.9724(2)$ & 158 & $-\mathrm{x}, 1-\mathrm{y},-\mathrm{z}$ \\
\hline O3-H3A $\cdots$ N4 & 1.79 & $2.6617(1)$ & 171 & $-1+x, y, z$ \\
\hline N5-H5A $\cdots$ N6 & 2.40 & $3.1614(2)$ & 149 & $1-x,-y, 1-z$ \\
\hline $\mathrm{N} 5-\mathrm{H} 5 \mathrm{~B} \cdots \mathrm{O} 4$ & 1.99 & $2.8882(2)$ & 176 & $1+\mathrm{x}, \mathrm{y}, \mathrm{z}$ \\
\hline $\mathrm{C} 2-\mathrm{H} 2 \cdots \mathrm{N} 5$ & 2.55 & $3.3970(2)$ & 148 & $1-\mathrm{x}, 1-\mathrm{y}, 1-\mathrm{z}$ \\
\hline $\mathrm{C} 3-\mathrm{H} 3 \cdots \mathrm{O} 4$ & 2.47 & $3.3078(2)$ & 146 & $-x, 1-y, 1-z$ \\
\hline $\mathrm{C} 4-\mathrm{H} 4 \cdots \mathrm{O} 2$ & 2.50 & $3.1804(2)$ & 129 & $-1+x, y, z$ \\
\hline $\mathrm{C} 11-\mathrm{H} 11 \cdots \mathrm{O} 2$ & 2.51 & $3.1981(2)$ & 130 & $1-x, 1-y,-z$ \\
\hline C18-H18B $\cdots$ F2 & 2.47 & $3.1655(2)$ & 127 & $\mathrm{x},-1+\mathrm{y}, \mathrm{z}$ \\
\hline C19-H19A $\cdots \mathrm{O} 1$ & 2.57 & $3.5031(2)$ & 158 & $-1+x,-1+y, z$ \\
\hline $\mathrm{C} 21-\mathrm{H} 21 \cdots \mathrm{F} 3$ & 2.55 & $3.2700(2)$ & 133 & Intra \\
\hline \multirow[t]{2}{*}{$\mathrm{C} 27-\mathrm{H} 27 \mathrm{~B} \cdots \mathrm{O} 4$} & 2.56 & $3.4457(2)$ & 151 & $\mathrm{x}, \mathrm{y}, \mathrm{z}$ \\
\hline & & $\mathrm{DBF} 0.5 \mathrm{SA} \supset \mathrm{CH}_{3} \mathrm{CN}$ & & \\
\hline
\end{tabular}




\begin{tabular}{|c|c|c|c|c|}
\hline $\mathrm{N} 1-\mathrm{H} 1 \cdots \mathrm{N} 2$ & 2.16 & $2.9866(6)$ & 158 & $-x, 1-y,-z$ \\
\hline O3-H3A $\cdots$ N3 & 1.77 & $2.6995(5)$ & 174 & $-1+x, y, z$ \\
\hline N5-H5A $\cdots$ O4 & 1.99 & $2.8692(5)$ & 173 & $1+\mathrm{x}, \mathrm{y}, \mathrm{z}$ \\
\hline N5-H5B $\cdots$ N6 & 2.37 & $3.1386(6)$ & 146 & $1-x,-y, 1-z$ \\
\hline $\mathrm{C} 3-\mathrm{H} 3 \cdots \mathrm{O} 4$ & 2.46 & $3.3316(6)$ & 153 & $-x, 1-y, 1-z$ \\
\hline $\mathrm{C} 4-\mathrm{H} 4 \cdots \mathrm{O} 1$ & 2.51 & $3.2293(6)$ & 132 & $-1+x, y, z$ \\
\hline C9-H9…O1 & 2.53 & $3.2257(6)$ & 130 & $1-x, 1-y,-z$ \\
\hline $\mathrm{C} 10-\mathrm{H} 10 \cdots \mathrm{F} 2$ & 2.53 & $3.1423(6)$ & 122 & $-\mathrm{x}, 1-\mathrm{y},-\mathrm{z}$ \\
\hline $\mathrm{C} 22-\mathrm{H} 22 \mathrm{~B} \cdots \mathrm{F} 2$ & 2.44 & $3.1401(6)$ & 128 & $\mathrm{x},-1+\mathrm{y}, \mathrm{z}$ \\
\hline $\mathrm{C} 23-\mathrm{H} 23 \mathrm{~A} \cdots \mathrm{O} 2$ & 2.59 & $3.5251(7)$ & 159 & $-1+x,-1+y, z$ \\
\hline \multirow[t]{2}{*}{$\mathrm{C} 27-\mathrm{H} 27 \mathrm{~B} \cdots \mathrm{O} 4$} & 2.47 & $3.3721(6)$ & 152 & $\mathrm{x}, \mathrm{y}, \mathrm{z}$ \\
\hline & & DBF•0.5ADA & & \\
\hline $\mathrm{N} 1-\mathrm{H} 1 \cdots \mathrm{N} 2$ & 2.15 & $2.9608(1)$ & 156 & $-x, 1-y, 1-z$ \\
\hline O3-H3A $\cdots$ N4 & 1.79 & $2.6805(1)$ & 172 & $3 / 2-x,-1 / 2+y, 1 / 2-z$ \\
\hline N5-H5A $\cdots$ O4 & 2.08 & $2.9422(1)$ & 170 & $3 / 2-x, 1 / 2+y, 1 / 2-z$ \\
\hline \multirow[t]{2}{*}{$\mathrm{C} 2-\mathrm{H} 2 \cdots \mathrm{O} 4$} & 2.50 & $3.3749(1)$ & 152 & $-1 / 2+x, 1 / 2-y,-1 / 2+z$ \\
\hline & & DBF•isoPA $\supset \mathrm{H}_{2} \mathrm{O}$ & & \\
\hline O3-H3A $\cdots$ N4 & 1.99 & $2.8606(1)$ & 162 & $-x, 1-y, 1-z$ \\
\hline $\mathrm{O} 3-\mathrm{H} 3 \mathrm{~B} \cdots \mathrm{N} 5$ & 2.24 & $3.0181(1)$ & 169 & $\mathrm{x}, \mathrm{y}, \mathrm{z}$ \\
\hline N5-H5A $\cdots$ N3 & 2.22 & $3.0664(1)$ & 178 & 1-x,1-y,1-z \\
\hline N5-H5B $\cdots$ O3 & 2.40 & $3.1404(1)$ & 147 & $-x, 1-y, 1-z$ \\
\hline N6-H6A $\cdots$ O3 & 1.98 & $2.8961(1)$ & 177 & $\mathrm{x}, \mathrm{y}, \mathrm{z}$ \\
\hline N6-H6B $\cdots$ N1 & 1.99 & $2.8427(1)$ & 176 & $1-x, 1-y, 1-z$ \\
\hline N6-H6C $\cdots \mathrm{O} 2$ & 1.98 & $2.8581(1)$ & 155 & $-1+x, y,-1+z$ \\
\hline $\mathrm{C} 3-\mathrm{H} 3 \cdots \mathrm{O} 1$ & 2.51 & $3.1385(1)$ & 124 & $1+\mathrm{x}, \mathrm{y}, \mathrm{z}$ \\
\hline $\mathrm{C} 8-\mathrm{H} 8 \cdots \mathrm{O} 1$ & 2.48 & $3.1106(1)$ & 123 & Intra \\
\hline $\mathrm{C} 23-\mathrm{H} 23 \mathrm{~A} \cdots \mathrm{O} 1$ & 2.32 & $3.2204(1)$ & 152 & $\mathrm{x}, \mathrm{y},-1+\mathrm{z}$ \\
\hline \multirow[t]{2}{*}{$\mathrm{C} 26-\mathrm{H} 26 \mathrm{C} \cdots \mathrm{O} 2$} & 2.54 & $3.2680(1)$ & 131 & $-1+x, y,-1+z$ \\
\hline & & $\mathrm{DBF} \cdot \operatorname{secBA} \supset \mathrm{H}_{2} \mathrm{O}$ & & \\
\hline O3-H3A $\cdots$ N4 & 2.00 & $2.8219(1)$ & 164 & $-x, 1-y, 1-z$ \\
\hline $\mathrm{O} 3-\mathrm{H} 3 \mathrm{~B} \cdots \mathrm{N} 5$ & 2.23 & $3.0456(1)$ & 167 & $\mathrm{x}, \mathrm{y}, \mathrm{z}$ \\
\hline N5-H5A $\cdots$ N3 & 2.19 & $3.0632(1)$ & 177 & $1-x, 1-y, 1-z$ \\
\hline N5-H5B $\cdots \mathrm{O} 3$ & 2.48 & $3.1828(1)$ & 142 & $-x, 1-y, 1-z$ \\
\hline N6-H6A $\cdots \mathrm{O} 2$ & 1.95 & $2.8481(1)$ & 168 & $-1+x, y,-1+z$ \\
\hline N6-H6B $\cdots \mathrm{O} 3$ & 1.97 & $2.8988(1)$ & 172 & $\mathrm{x}, \mathrm{y}, \mathrm{z}$ \\
\hline
\end{tabular}




\begin{tabular}{|c|c|c|c|c|}
\hline N6-H6C $\cdots$ F3 & 2.52 & $2.9799(1)$ & 115 & $1-x, 1-y, 1-z$ \\
\hline N6-H6C $\cdots \mathrm{N} 1$ & 2.00 & $2.8484(1)$ & 174 & $1-x, 1-y, 1-z$ \\
\hline $\mathrm{C} 3-\mathrm{H} 3 \cdots \mathrm{O} 1$ & 2.53 & $3.1654(1)$ & 124 & $1+x, y, z$ \\
\hline $\mathrm{C} 8-\mathrm{H} 8 \cdots \mathrm{O} 1$ & 2.51 & $3.1347(1)$ & 124 & Intra \\
\hline $\mathrm{C} 21-\mathrm{H} 21 \mathrm{~A} \cdots \mathrm{O} 1$ & 2.47 & $3.2379(1)$ & 135 & $\mathrm{x}, \mathrm{y},-1+\mathrm{z}$ \\
\hline $\mathrm{C} 24-\mathrm{H} 24 \mathrm{C} \cdots \mathrm{F} 3$ & 2.54 & $3.1517(1)$ & 120 & $1-x, 1-y, 1-z$ \\
\hline $\mathrm{C} 24^{\prime}-\mathrm{H} 25 \cdots \mathrm{N} 6$ & 2.11 & $2.4008(1)$ & 111 & Intra \\
\hline \multirow[t]{2}{*}{$\mathrm{C} 24-\mathrm{H} 25^{\prime} \cdots \mathrm{N} 6$} & 2.06 & $2.4737(1)$ & 125 & Intra \\
\hline & & $\mathrm{DBF} \bullet$ isoBA $\supset \mathrm{H}_{2} \mathrm{O}$ & & \\
\hline O3-H1A $\cdots$ N4 & 2.02 & $2.8858(1)$ & 162 & $-\mathrm{x}, 1-\mathrm{y}, 1-\mathrm{z}$ \\
\hline O3-H1B $\cdots$ N5 & 2.24 & $3.1252(2)$ & 169 & $\mathrm{x}, \mathrm{y}, \mathrm{z}$ \\
\hline N5-H5A $\cdots$ N3 & 2.21 & $3.0702(2)$ & 178 & $1-x, 1-y, 1-z$ \\
\hline N5-H5B $\cdots$ O3 & 2.57 & $3.2687(2)$ & 145 & $-x, 1-y, 1-z$ \\
\hline N6-H6A $\cdots$ F3 & 2.47 & $2.8864(1)$ & 109 & $1-x, 1-y, 1-z$ \\
\hline N6-H6A $\cdots$ N1 & 1.92 & $2.7846(1)$ & 161 & $1-x, 1-y, 1-z$ \\
\hline N6-H6B $\cdots \mathrm{O} 2$ & 1.95 & $2.8485(1)$ & 174 & $-1+\mathrm{x}, \mathrm{y},-1+\mathrm{z}$ \\
\hline N6-H6C $\cdots \mathrm{O} 3$ & 2.04 & $2.9279(2)$ & 170 & $\mathrm{x}, \mathrm{y}, \mathrm{z}$ \\
\hline $\mathrm{C} 3-\mathrm{H} 3 \cdots \mathrm{O} 1$ & 2.57 & $3.1030(2)$ & 116 & $1+x, y, z$ \\
\hline $\mathrm{C} 12-\mathrm{H} 12 \cdots \mathrm{O} 1$ & 2.57 & $3.1704(2)$ & 121 & Intra \\
\hline \multirow[t]{2}{*}{$\mathrm{C} 18-\mathrm{H} 18 \mathrm{~A} \cdots \mathrm{O} 1$} & 2.49 & $3.2345(2)$ & 133 & $\mathrm{x}, \mathrm{y},-1+\mathrm{z}$ \\
\hline & & DBF•cycloHA $\supset \mathrm{H}_{2} \mathrm{O}$ & & \\
\hline $\mathrm{O} 3-\mathrm{H} 3 \mathrm{C} \cdots \mathrm{N} 5$ & 2.13 & $3.0580(2)$ & 166 & $-x, 1-y,-z$ \\
\hline $\mathrm{O} 3-\mathrm{H} 3 \mathrm{~B} \cdots \mathrm{N} 4$ & 1.93 & $2.8309(2)$ & 165 & $1+\mathrm{x}, \mathrm{y}, \mathrm{z}$ \\
\hline N5-H5A $\cdots$ N3 & 2.20 & $3.0626(2)$ & 177 & $-\mathrm{x}, 1-\mathrm{y},-\mathrm{z}$ \\
\hline N5-H5B $\cdots \mathrm{O} 3$ & 2.52 & $3.2683(2)$ & 147 & $-1+\mathrm{x}, \mathrm{y}, \mathrm{z}$ \\
\hline N6-H6A $\cdots \mathrm{O} 1$ & 1.97 & $2.8259(2)$ & 155 & $1-x, 1-y, 1-z$ \\
\hline N6-H6B $\cdots$ F3 & 2.47 & $2.9407(2)$ & 112 & $\mathrm{x}, \mathrm{y}, \mathrm{z}$ \\
\hline N6-H6B $\cdots$ N1 & 1.94 & $2.8629(2)$ & 175 & $\mathrm{x}, \mathrm{y}, \mathrm{z}$ \\
\hline N6-H6C $\cdots \mathrm{O} 3$ & 1.99 & $2.9103(2)$ & 177 & $\mathrm{x}, \mathrm{y}, \mathrm{z}$ \\
\hline C4A-H4A $\cdots$ F2A & 2.08 & $2.5058(2)$ & 105 & $1-x,-y, 1-z$ \\
\hline $\mathrm{C} 12-\mathrm{H} 12 \cdots \mathrm{O} 2$ & 2.50 & $3.1260(2)$ & 123 & Intra \\
\hline C19-H19A $\cdots$ F2 & 2.53 & $3.4353(2)$ & 154 & $\mathrm{x}, \mathrm{y},-1+\mathrm{z}$ \\
\hline \multirow[t]{2}{*}{ C28-H28C $\cdots$ F1 } & 2.55 & $3.2789(2)$ & 131 & $-\mathrm{x}, \mathrm{y}, \mathrm{z}$ \\
\hline & & $\mathrm{DBF} \cdot \mathrm{EN} \supset \mathrm{H}_{2} \mathrm{O}$ & & \\
\hline $\mathrm{O} 3-\mathrm{H} 3 \mathrm{~A} \cdots \mathrm{N} 6$ & 1.96 & $2.8061(2)$ & 163 & $\mathrm{x},-1+\mathrm{y}, \mathrm{z}$ \\
\hline
\end{tabular}




\begin{tabular}{|c|c|c|c|c|}
\hline O3-H3B $\cdots$ N3 & 2.29 & $3.1493(2)$ & 171 & $3 / 2-x,-1 / 2+y, 1 / 2-z$ \\
\hline N5-H5A $\cdots$ N3 & 2.59 & $3.3563(2)$ & 162 & $3 / 2-x,-1 / 2+y, 1 / 2-z$ \\
\hline N5-H5B $\cdots$ N4 & 2.18 & $3.0651(2)$ & 167 & $3 / 2-x, 1 / 2+y, 1 / 2-z$ \\
\hline N6-H6A $\cdots \mathrm{O} 1$ & 2.37 & $3.2577(2)$ & 173 & $3 / 2-x, 1 / 2+y, 1 / 2-z$ \\
\hline N6-H6B $\cdots \mathrm{O} 2$ & 2.46 & $3.3252(2)$ & 154 & $-1 / 2+x, 1 / 2-y, 1 / 2+z$ \\
\hline N7-H7A $\cdots$ F3 & 2.49 & $3.0725(2)$ & 123 & $3 / 2-x, 1 / 2+y, 1 / 2-z$ \\
\hline N7-H7A $\cdots$ N1 & 1.98 & $2.8585(2)$ & 165 & $3 / 2-x, 1 / 2+y, 1 / 2-z$ \\
\hline N7-H7B $\cdots \mathrm{O} 1$ & 1.90 & $2.7960(2)$ & 170 & $-1 / 2+x, 1 / 2-y, 1 / 2+z$ \\
\hline N7-H7C $\cdots \mathrm{O} 3$ & 1.87 & $2.7250(2)$ & 160 & $\mathrm{x}, \mathrm{y}, \mathrm{z}$ \\
\hline $\mathrm{C} 21-\mathrm{H} 21 \mathrm{~B} \cdots \mathrm{F} 2$ & 2.54 & $3.4740(2)$ & 159 & $-1 / 2+x,-1 / 2-y, 1 / 2+z$ \\
\hline
\end{tabular}

Table S2. Fourier difference maps $\left(F_{o} \quad F_{c}\right)$ obtained from X-ray diffraction data. All maps were calculated using phases with the hydrogen atom of interest removed from the model and through the plane generated by the atoms as shown in the map.

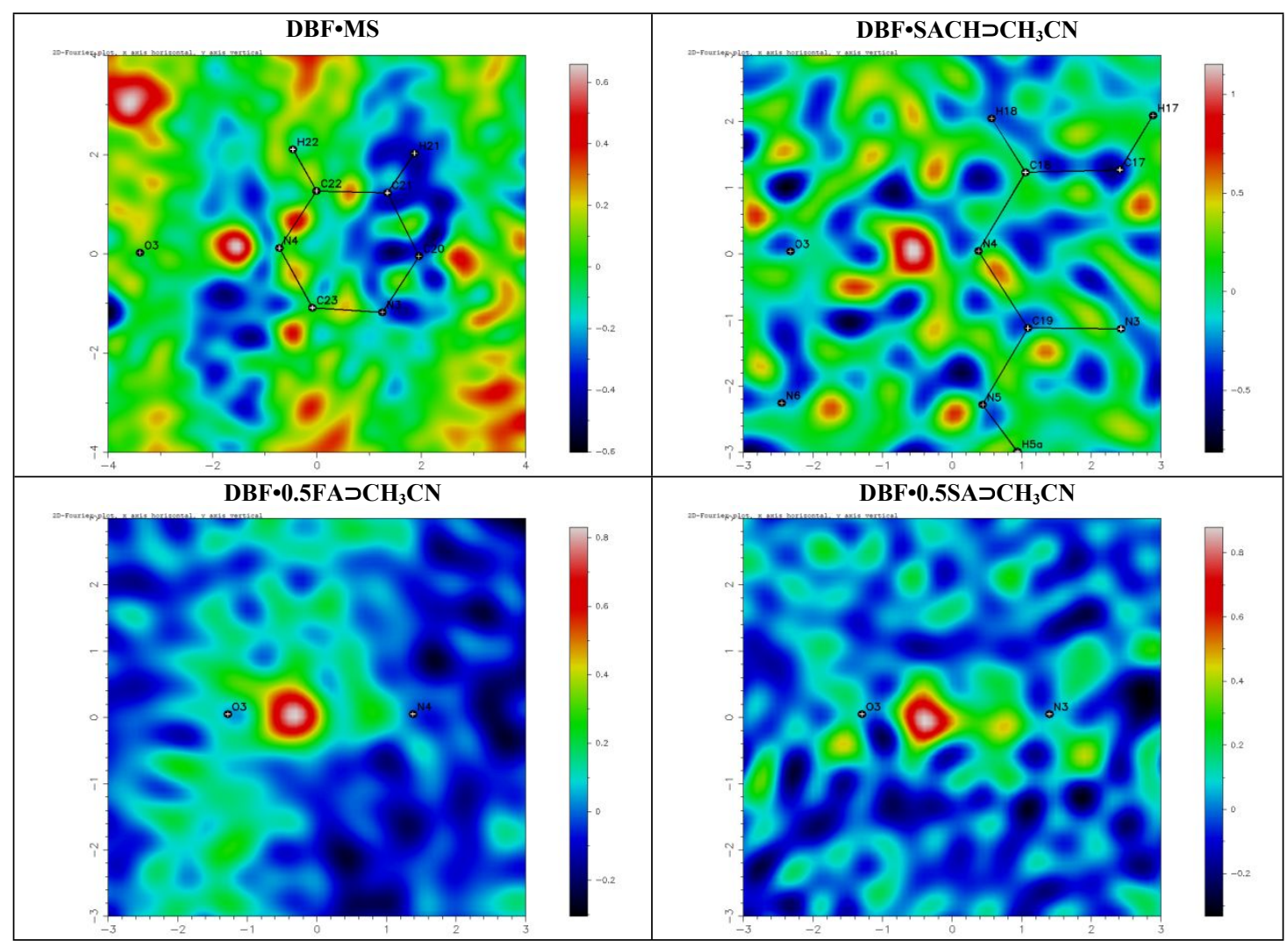




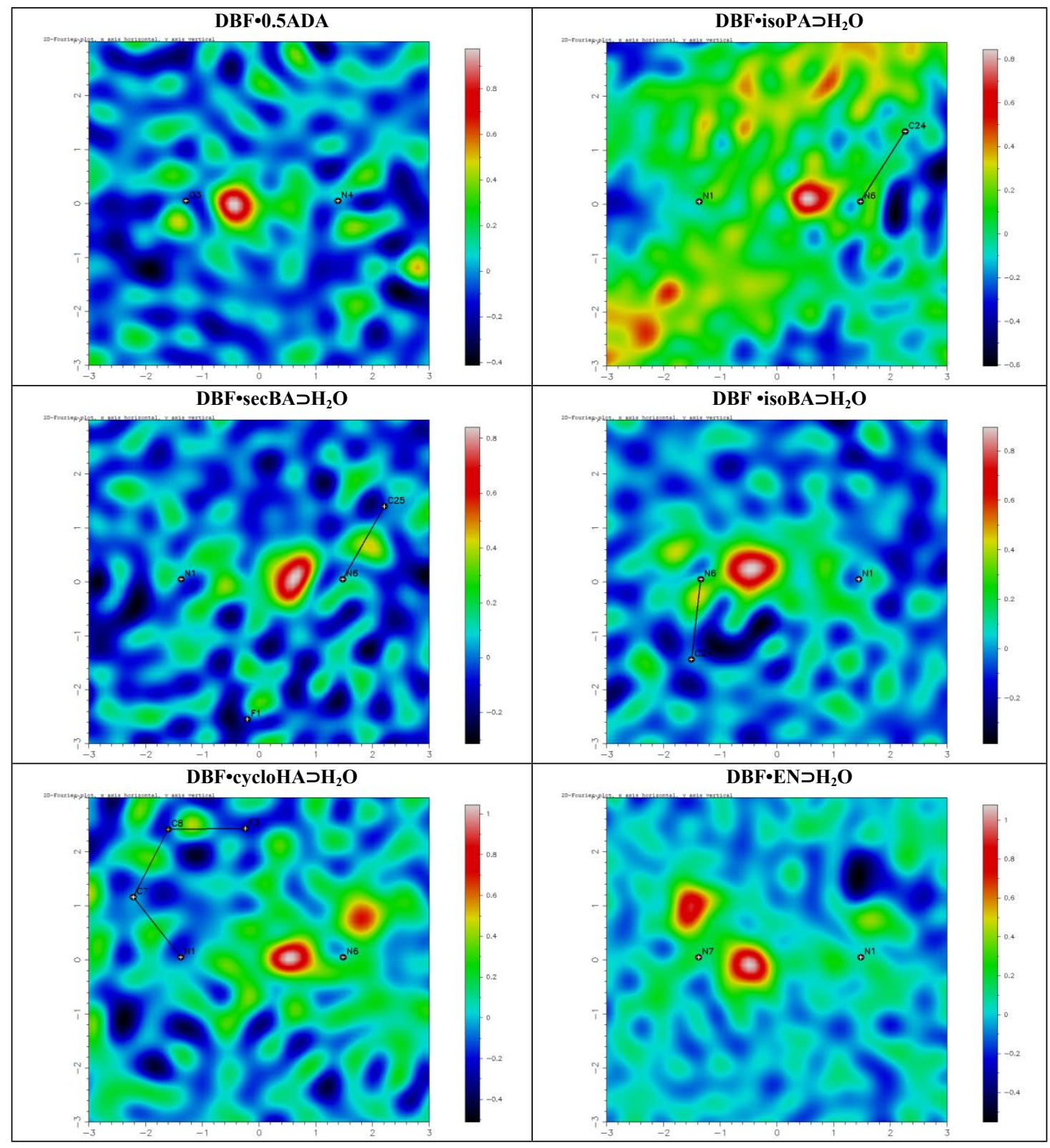




\section{Powder X-ray Diffraction Analysis}

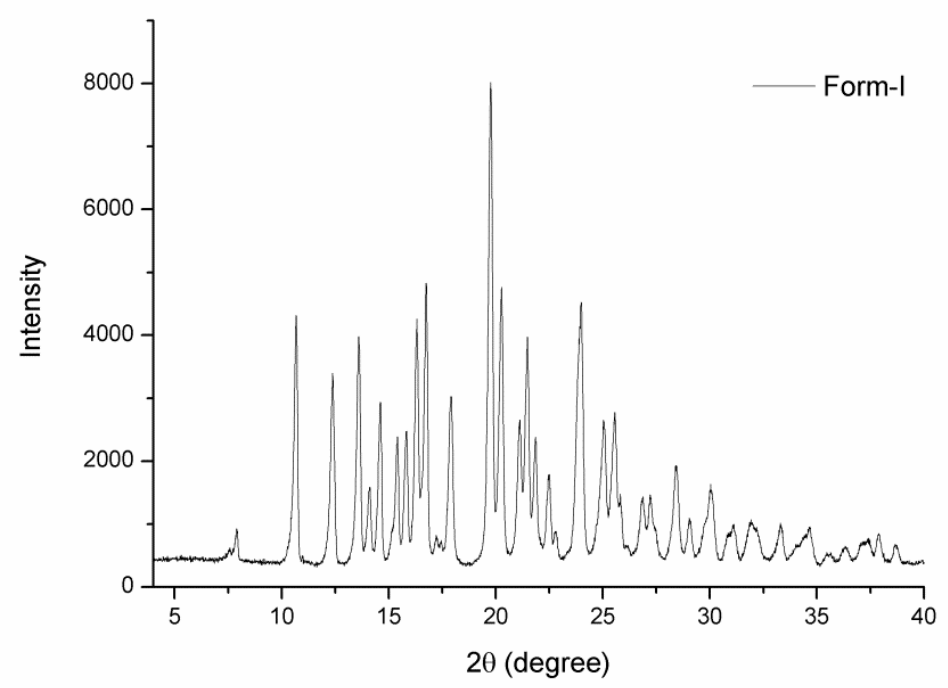

Figure S1. PXRD of DBF Form-I obtained after neutralization of DBF•MS salt.

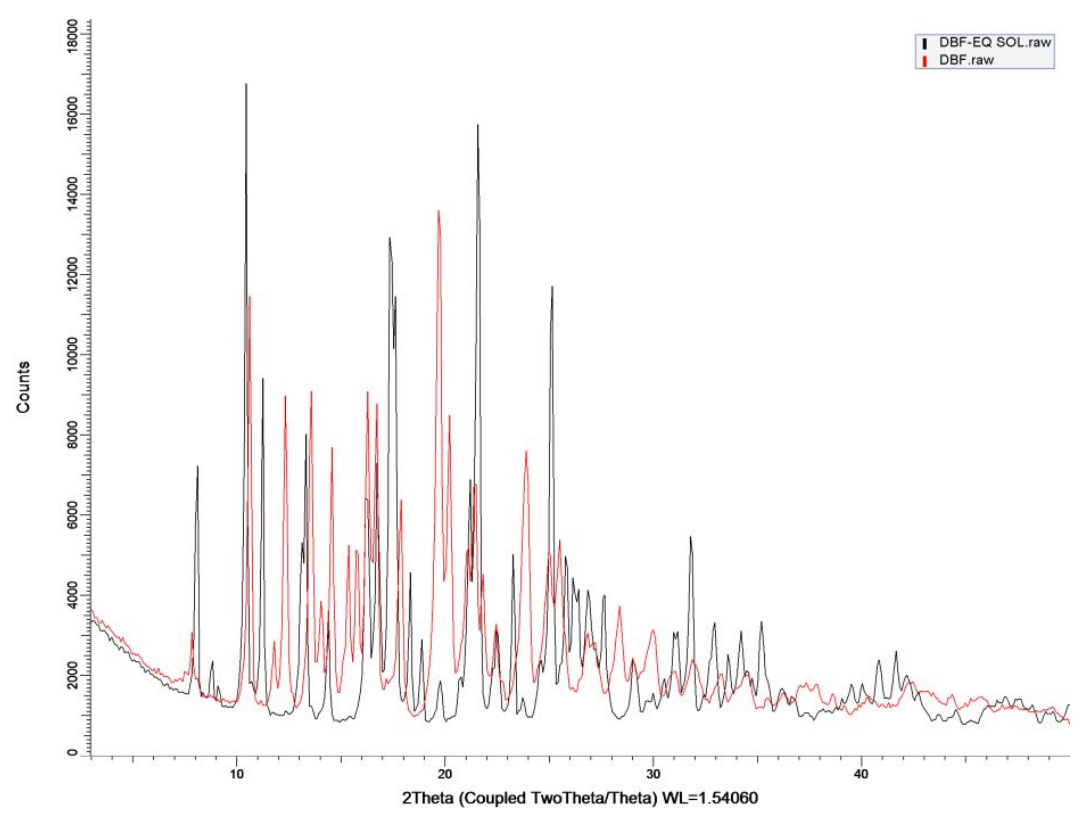

Figure S2. Overlay of PXRD patterns of neutral DBF at the end of the equilibrium solubility (black) experiment with neutral DBF (red), which indicates the conversion of DBF to new solid phase under $\mathrm{pH} 1.2$ aq. $\mathrm{HCl}$ conditions. 


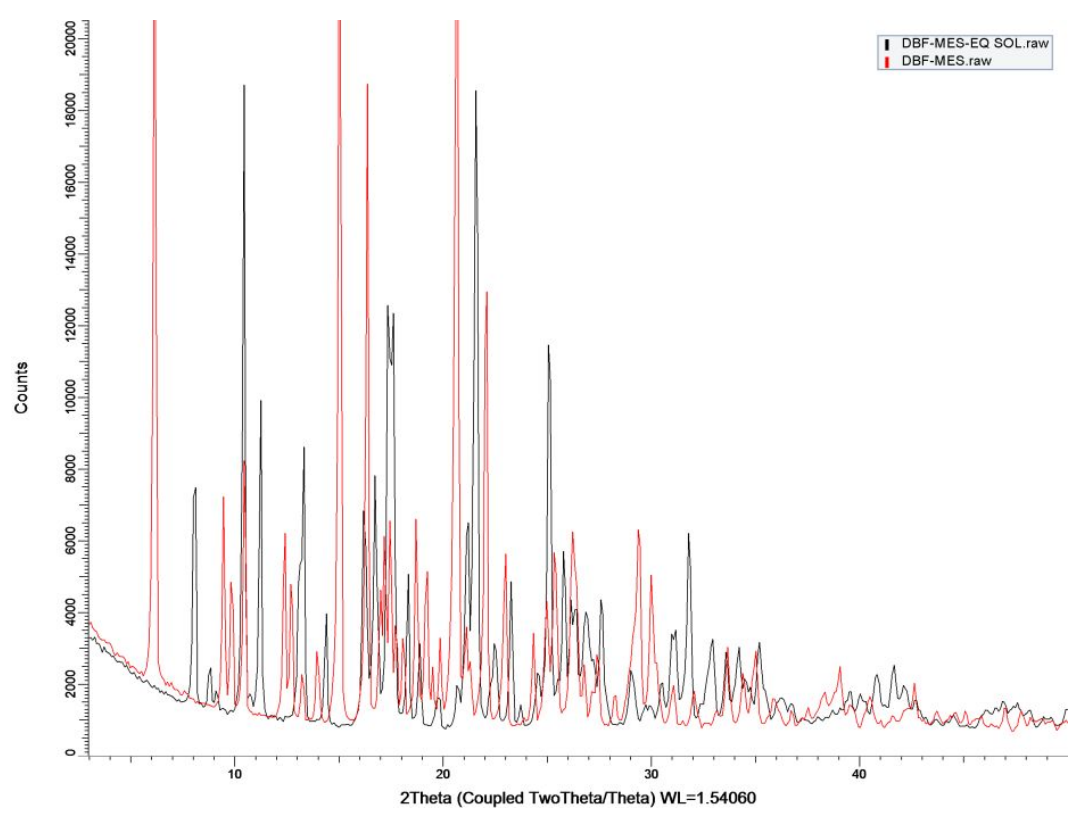

Figure S3. Overlay of PXRD patterns of DBF•MS salt at the end of the equilibrium solubility (black) experiment with DBF・MS salt (red), which indicates the conversion of DBF•MS salt to new solid form under $\mathrm{pH} 1.2$ aq. $\mathrm{HCl}$ conditions.

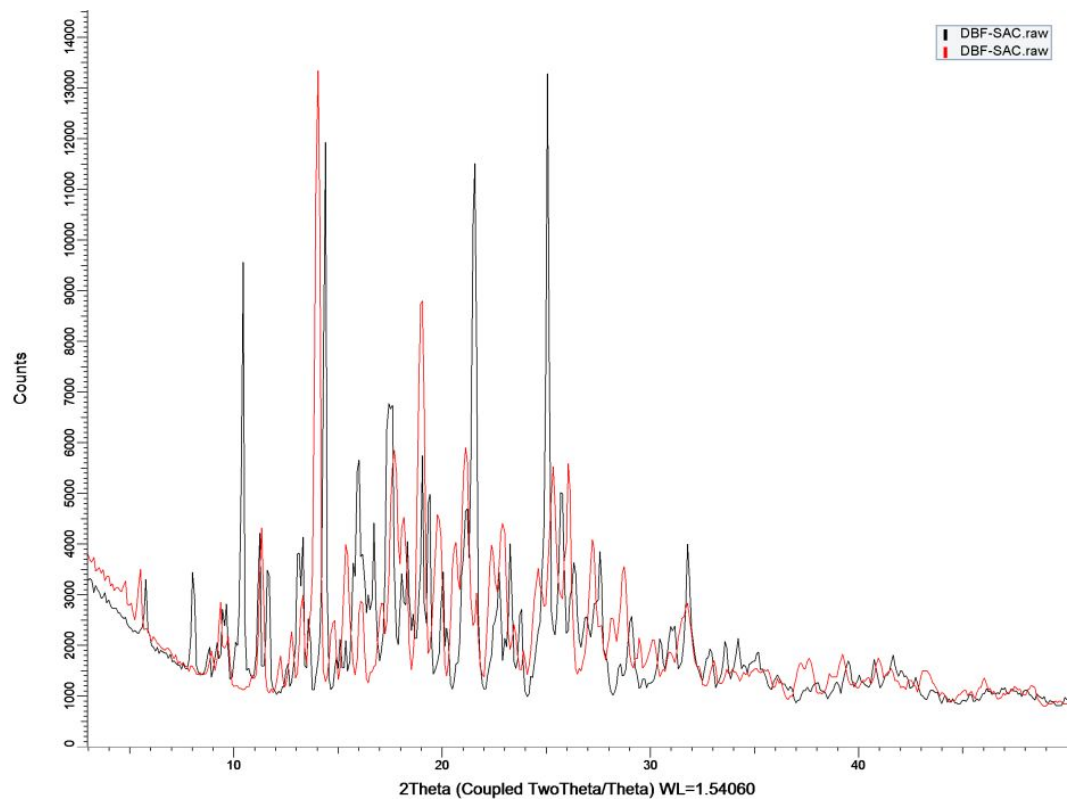

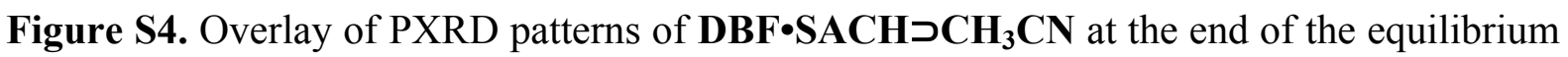
solubility (black) experiment with $\mathbf{D B F} \cdot \mathbf{S A C H} \supset \mathbf{C H}_{3} \mathbf{C N}$ salt (red), which indicates the conversion of $\mathbf{D B F} \cdot \mathbf{S A C H} \supset \mathbf{C H}_{3} \mathbf{C N}$ salt to new solid form under $\mathrm{pH} 1.2$ aq. $\mathrm{HCl}$ conditions. 


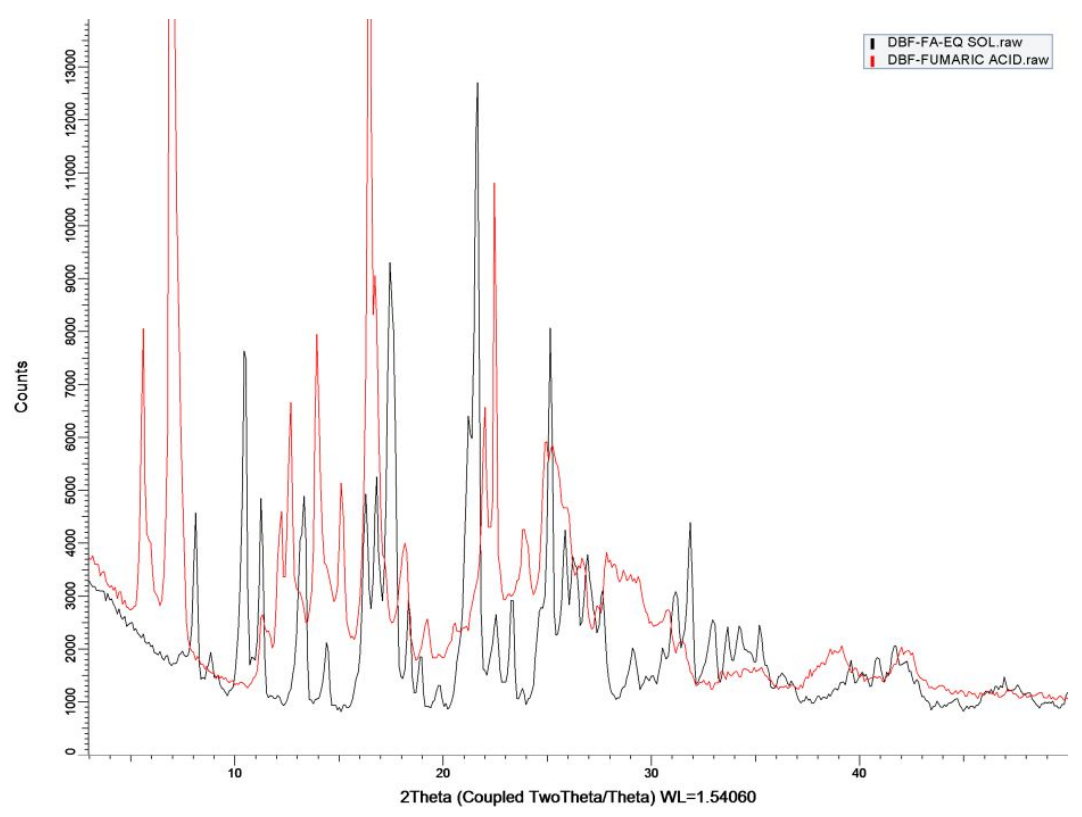

Figure S5. Overlay of PXRD patterns of DBF•0.5FA $\supset \mathbf{C H}_{3} \mathbf{C N}$ at the end of the equilibrium solubility (black) experiment with DBF•0.5FA $\supset \mathbf{C H}_{3} \mathbf{C N}$ cocrystal (red), which indicates the conversion of $\mathbf{D B F} \bullet \mathbf{0 . 5 F A} \supset \mathbf{C H}_{3} \mathbf{C N}$ cocrystal to new solid form under $\mathrm{pH} 1.2$ aq. $\mathrm{HCl}$ conditions.

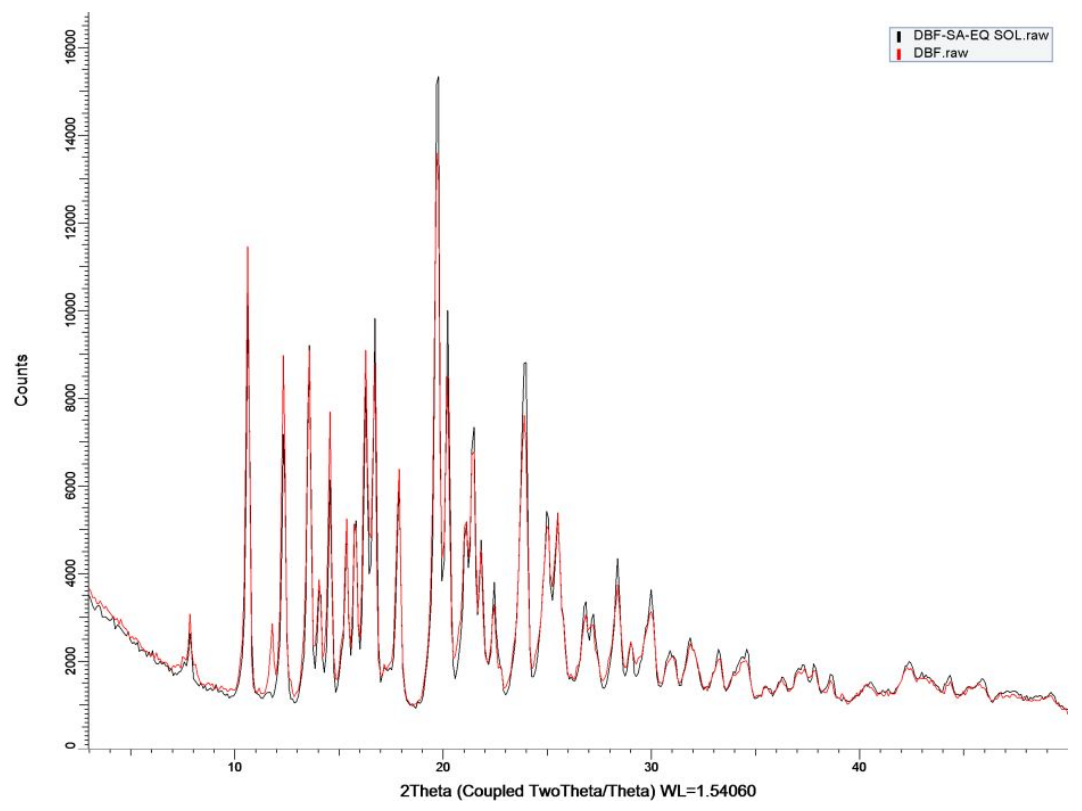

Figure S6. Overlay of PXRD patterns of $\mathrm{DBF} \bullet \mathbf{0 . 5 S A} \supset \mathrm{CH}_{3} \mathrm{CN}$ at the end of the equilibrium solubility (black) experiment with DBF neutral (red), which indicates the conversion of DBF•0.5SA $\mathbf{C H}_{3} \mathbf{C N}$ cocrystal to DBF neutral under $\mathrm{pH} 1.2$ aq. $\mathrm{HCl}$ conditions. 


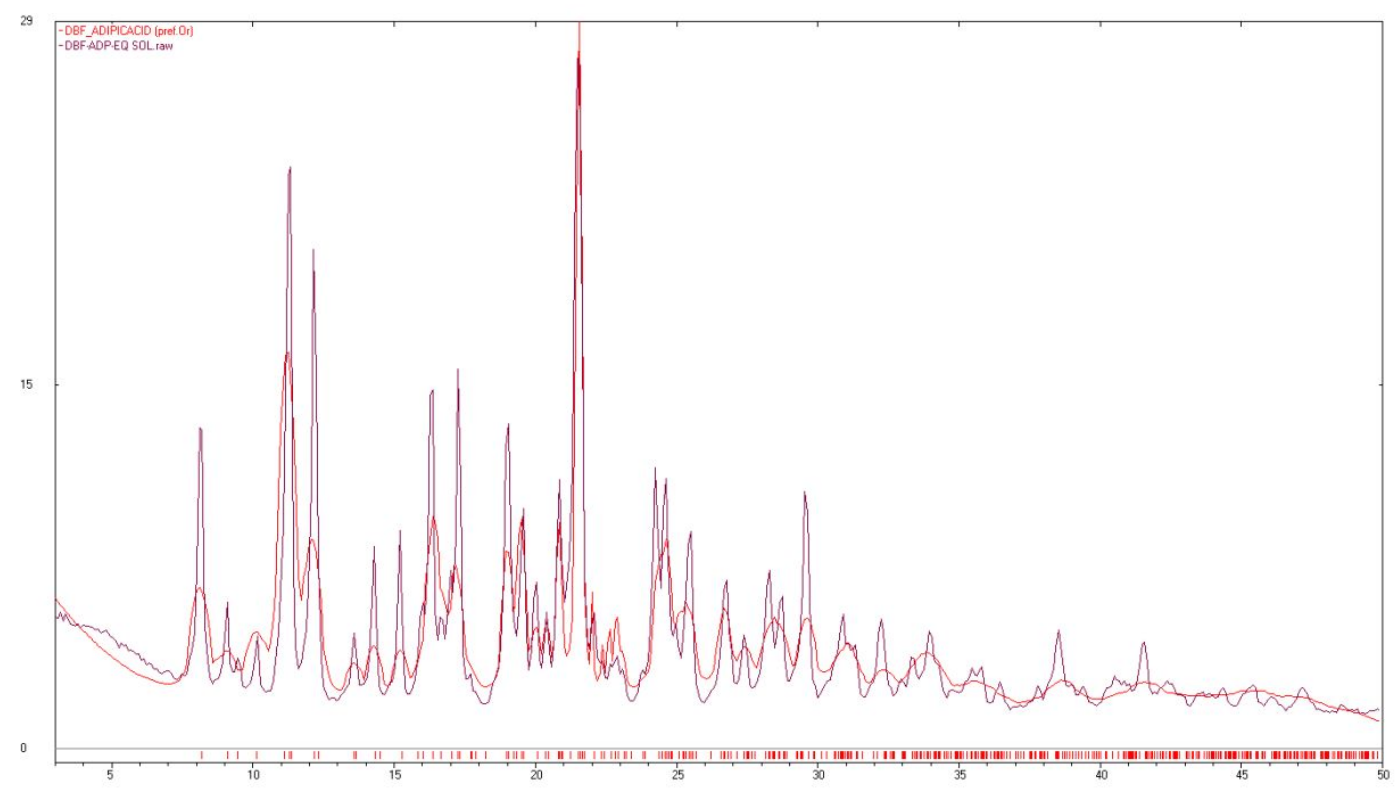

Figure S7. Overlay of PXRD patterns of DBF•0.5ADA cocrystal at the end of the equilibrium solubility (purple) experiment with DBF•ADA cocrystal (red) which are matching $(\mathrm{Rp}=15.84 \%$ and $\mathrm{Rwp}=21.13 \%)$. It indicates that $\mathbf{D B F} \bullet \mathbf{A D A}$ cocrystal is stable under $\mathrm{pH} 1.2$ aq. $\mathrm{HCl}$ conditions.

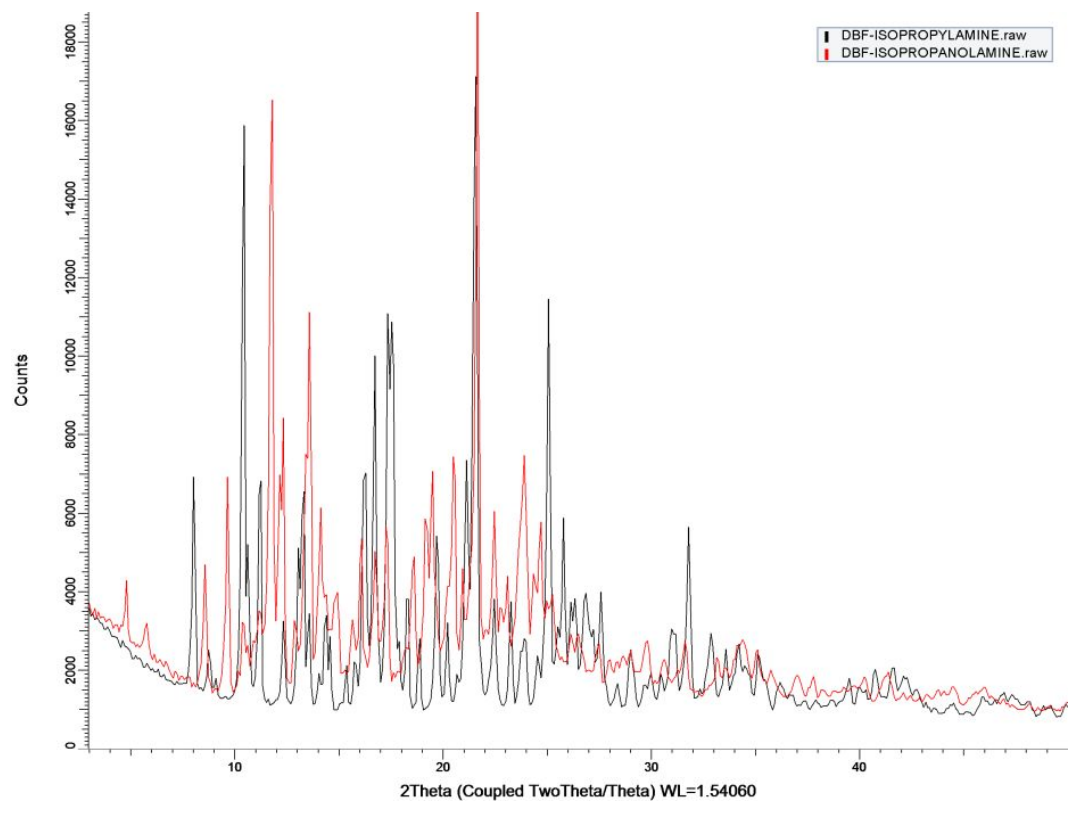

Figure S8. Overlay of PXRD patterns of DBF•isoPA $\supset \mathbf{H}_{2} \mathrm{O}$ salt at the end of the equilibrium solubility (black) experiment with $\mathbf{D B F} \cdot \mathbf{i s o P A} \boldsymbol{D H}_{\mathbf{2}} \mathbf{O}$ salt (red), which indicates the conversion of DBF•isoPA $\supset \mathbf{H}_{2} \mathbf{O}$ salt to new solid form under $\mathrm{pH} 1.2$ aq. $\mathrm{HCl}$ conditions. 


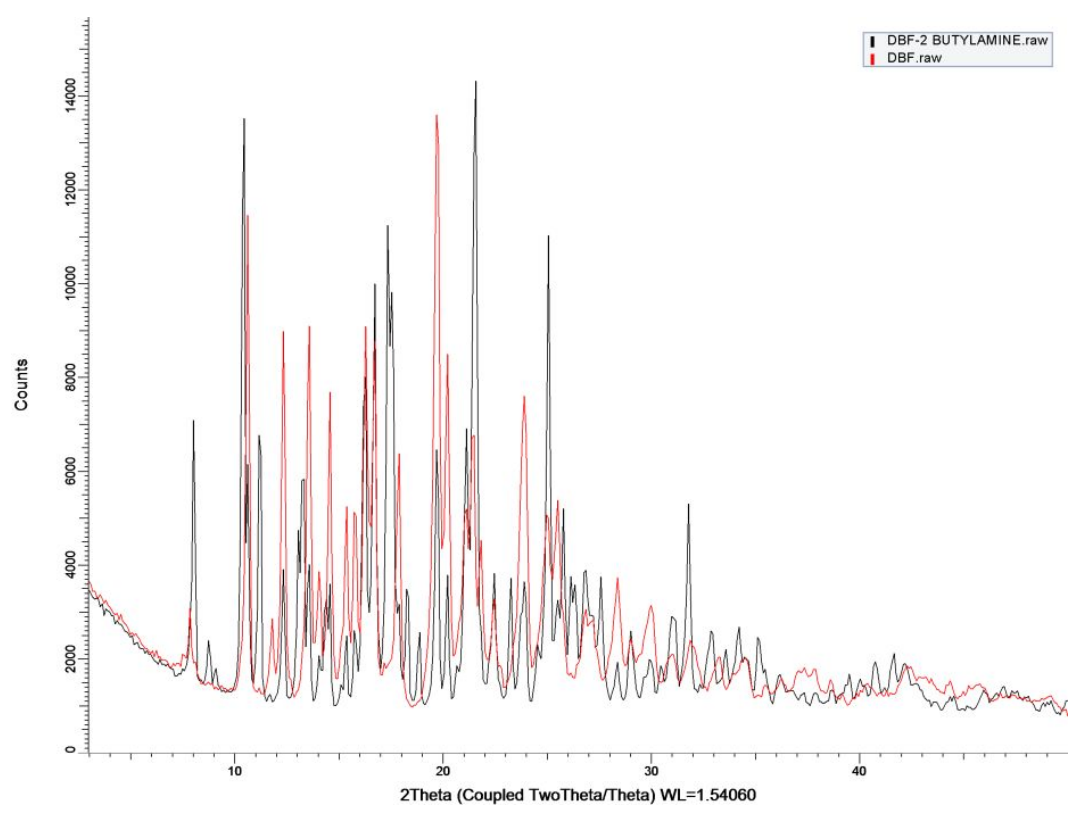

Figure S9. Overlay of PXRD patterns of DBF•secBA $\supset \mathbf{H}_{2} \mathbf{O}$ salt at the end of the equilibrium solubility (black) experiment with DBF neutral (red), which is neither matching with DBF•secBA $\supset \mathrm{H}_{2} \mathrm{O}$ salt nor DBF neutral but converting to new solid form under $\mathrm{pH} 1.2$ aq. $\mathrm{HCl}$ conditions.

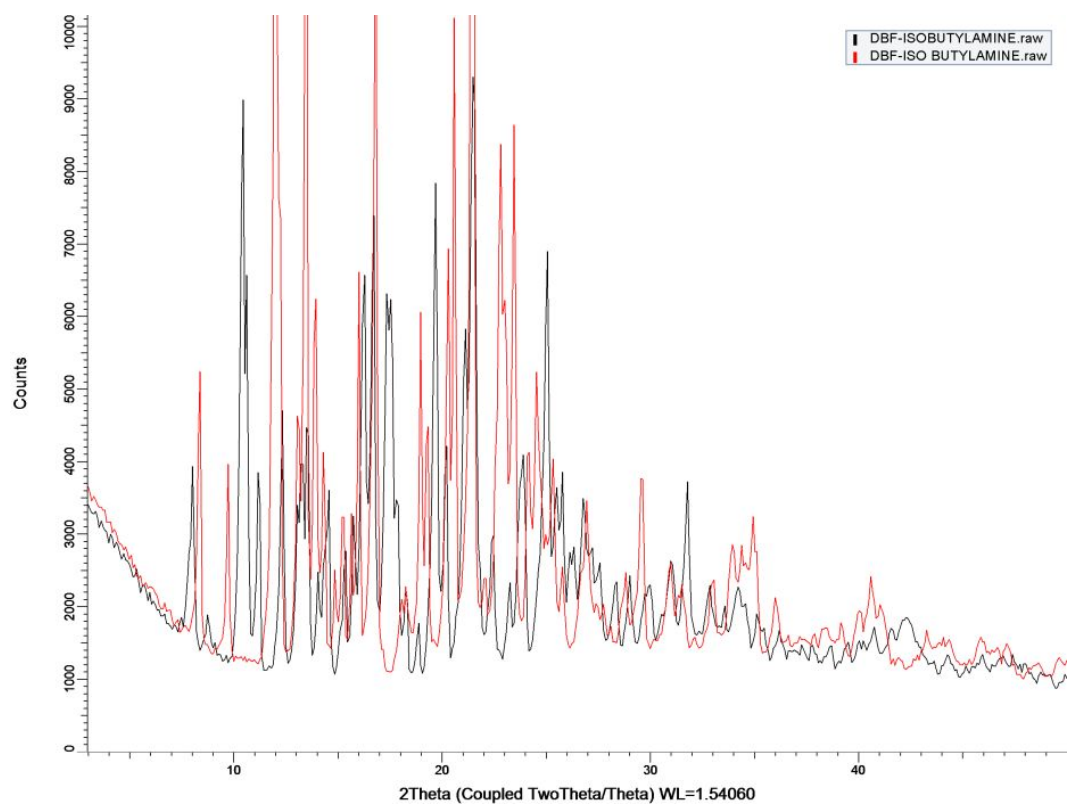

Figure S10. Overlay of PXRD patterns of DBF $\bullet$ isoBA $\supset \mathbf{H}_{2} \mathbf{O}$ salt at the end of the equilibrium solubility (black) experiment with DBF•isoBA $\supset_{\mathbf{2}} \mathbf{O}$ salt (red), which indicates the conversion of DBF•isoBA $\mathbf{D H}_{2} \mathbf{O}$ salt to new solid form under $\mathrm{pH} 1.2$ aq. $\mathrm{HCl}$ conditions. 


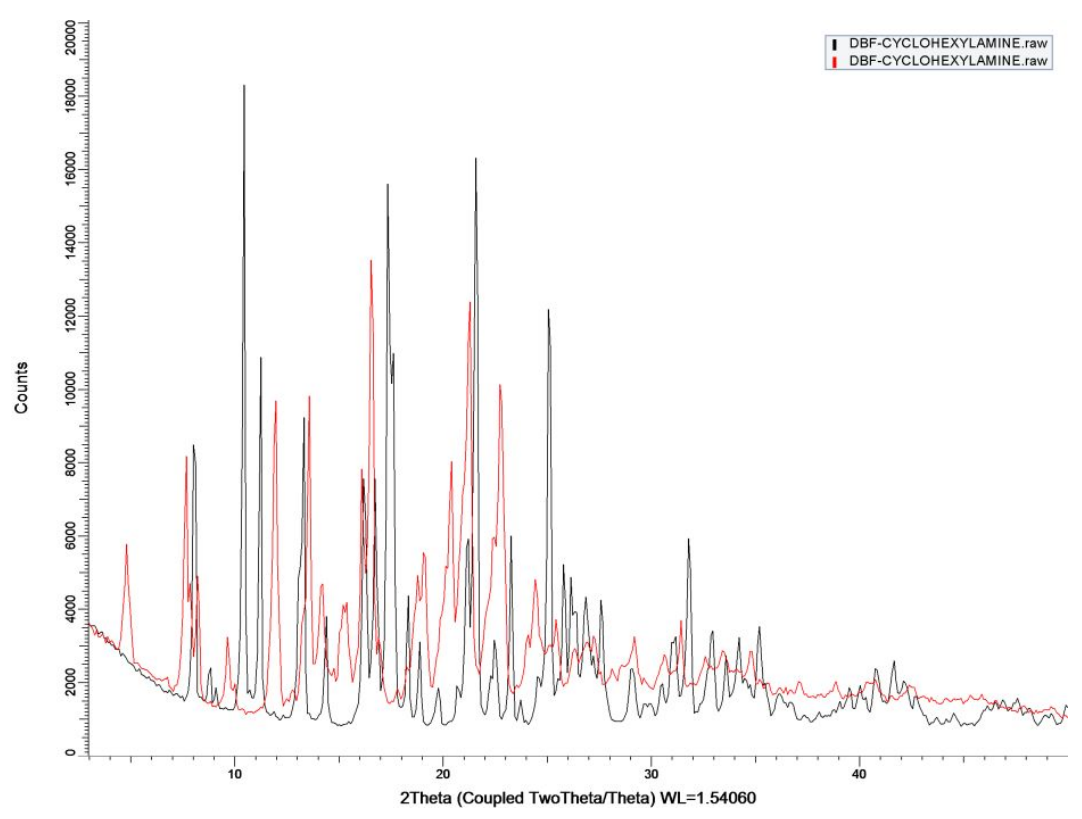

Figure S11. Overlay of PXRD patterns of DBF•cycloHA $\supset \mathrm{H}_{2} \mathrm{O}$ salt at the end of the equilibrium solubility (black) experiment with DBF•cycloHA $\supset \mathbf{H}_{2} \mathbf{O}$ salt (red), which indicates the conversion of DBF•cycloHA $\supset \mathbf{H}_{2} \mathrm{O}$ salt to new solid form under $\mathrm{pH} 1.2 \mathrm{aq}$. $\mathrm{HCl}$ conditions.

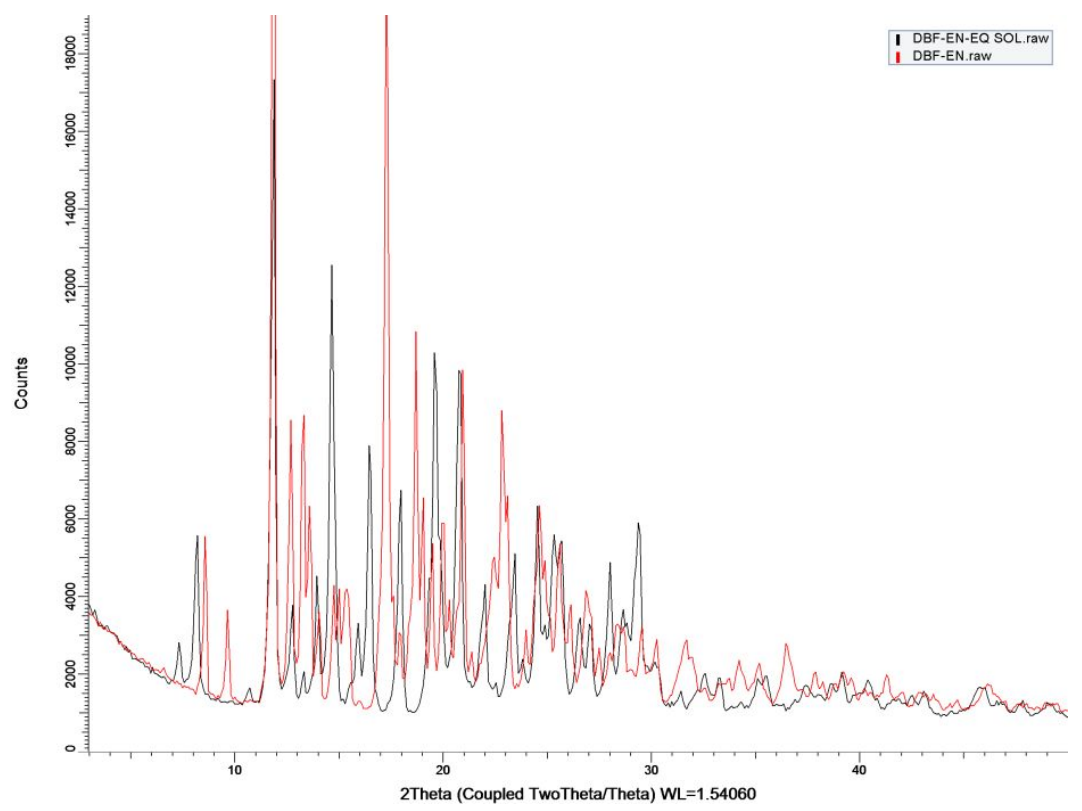

Figure S12. Overlay of PXRD patterns of DBF•ENつ $\mathbf{H}_{2} \mathbf{O}$ salt at the end of the equilibrium solubility (black) experiment with $\mathbf{D B F} \cdot \mathbf{E N} \mathbf{D H}_{2} \mathbf{O}$ salt (red), which indicates the conversion of $\mathbf{D B F} \bullet \mathbf{E N} \supset \mathrm{H}_{2} \mathrm{O}$ salt to new solid form under $\mathrm{pH} 1.2$ aq. $\mathrm{HCl}$ conditions. 


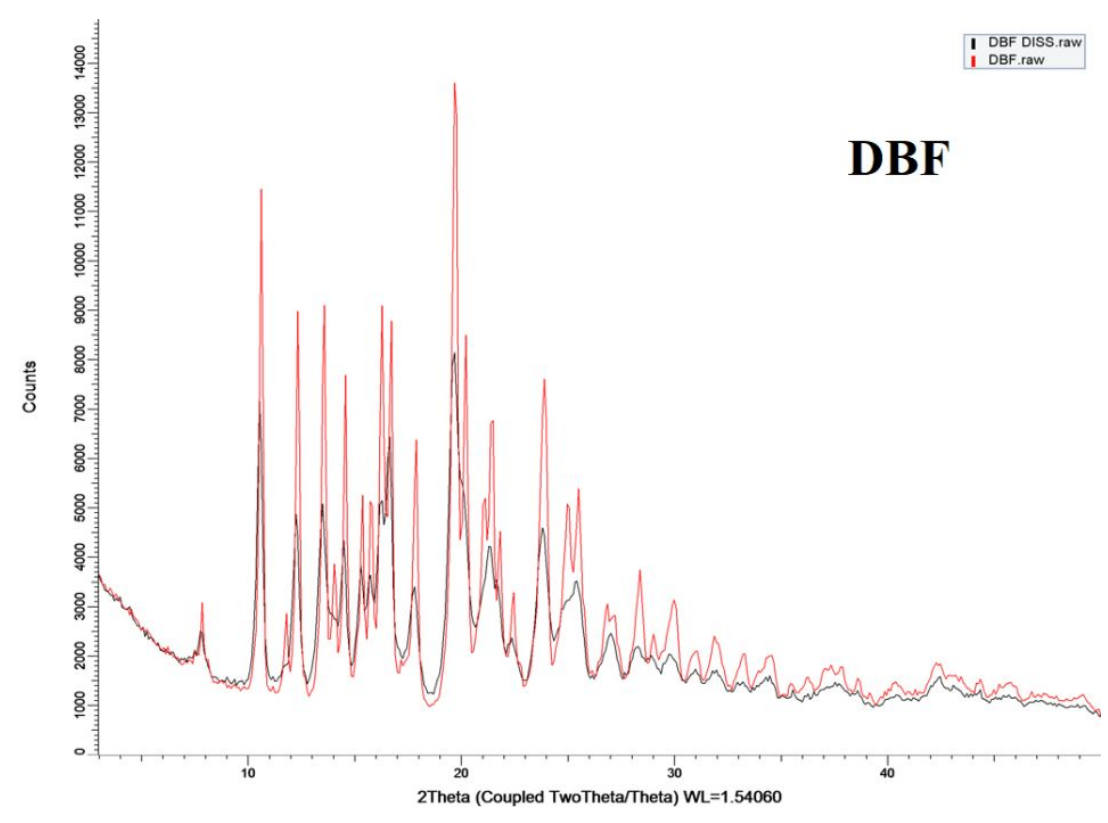

Figure S13. Overlay of PXRD patterns of DBF at the end of dissolution experiment (for $8 \mathrm{~h}$ ) in $\mathrm{pH} 1.2 \mathrm{HCl}$ buffer (black) matched with the calculated XRD pattern of DBF (red) indicating phase stability.

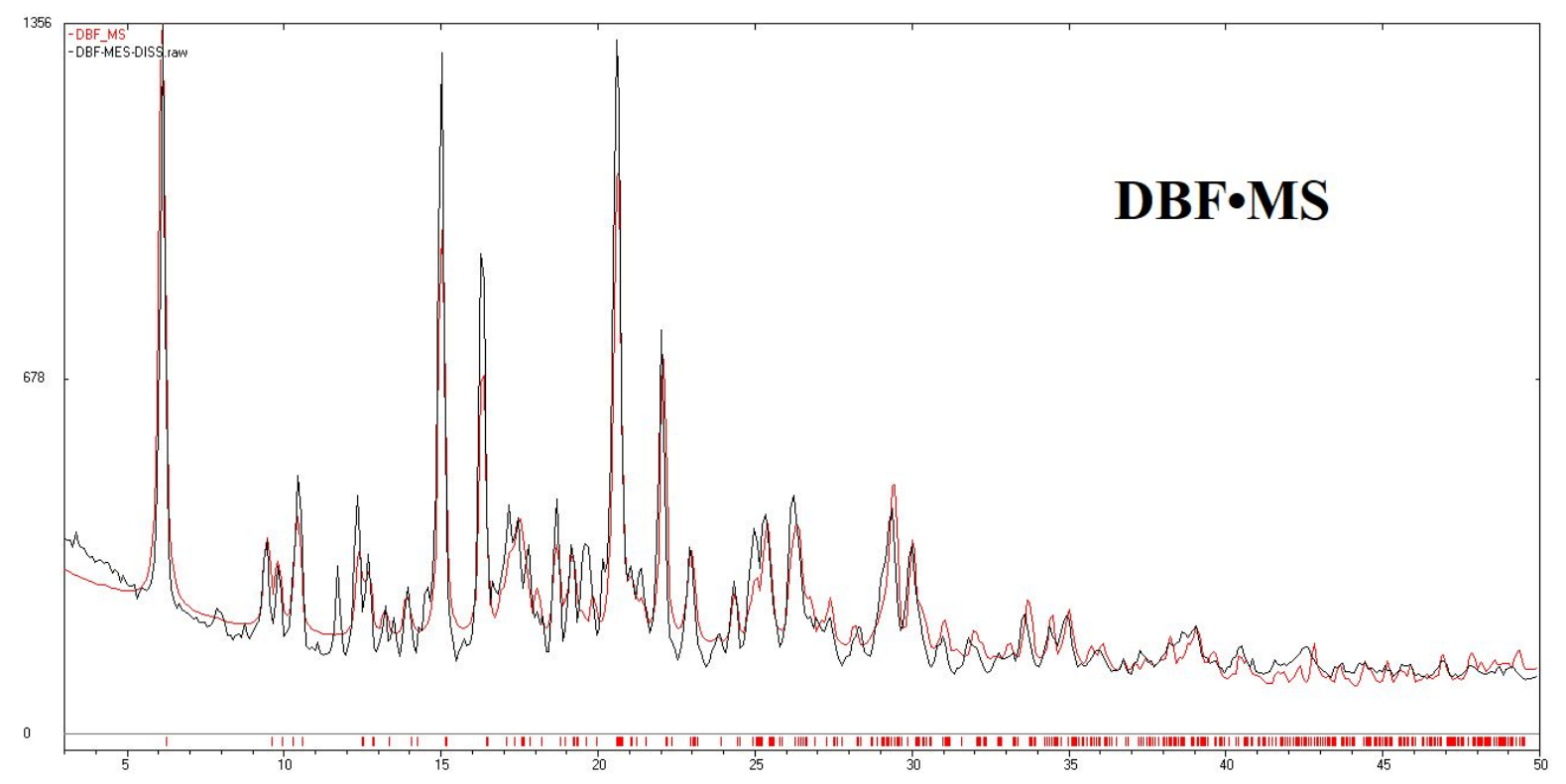

Figure S14. Overlay of PXRD patterns of DBF•MS salt at the end of dissolution experiment (for $8 \mathrm{~h}$ ) in $\mathrm{pH} 1.2 \mathrm{HCl}$ buffer (black) matched with the calculated XRD pattern of $\mathbf{D B F} \bullet \mathbf{M S}$ salt (red) indicating phase stability $(\mathrm{R} p=15.66 \%$ and $\mathrm{Rwp}=19.42 \%)$. 


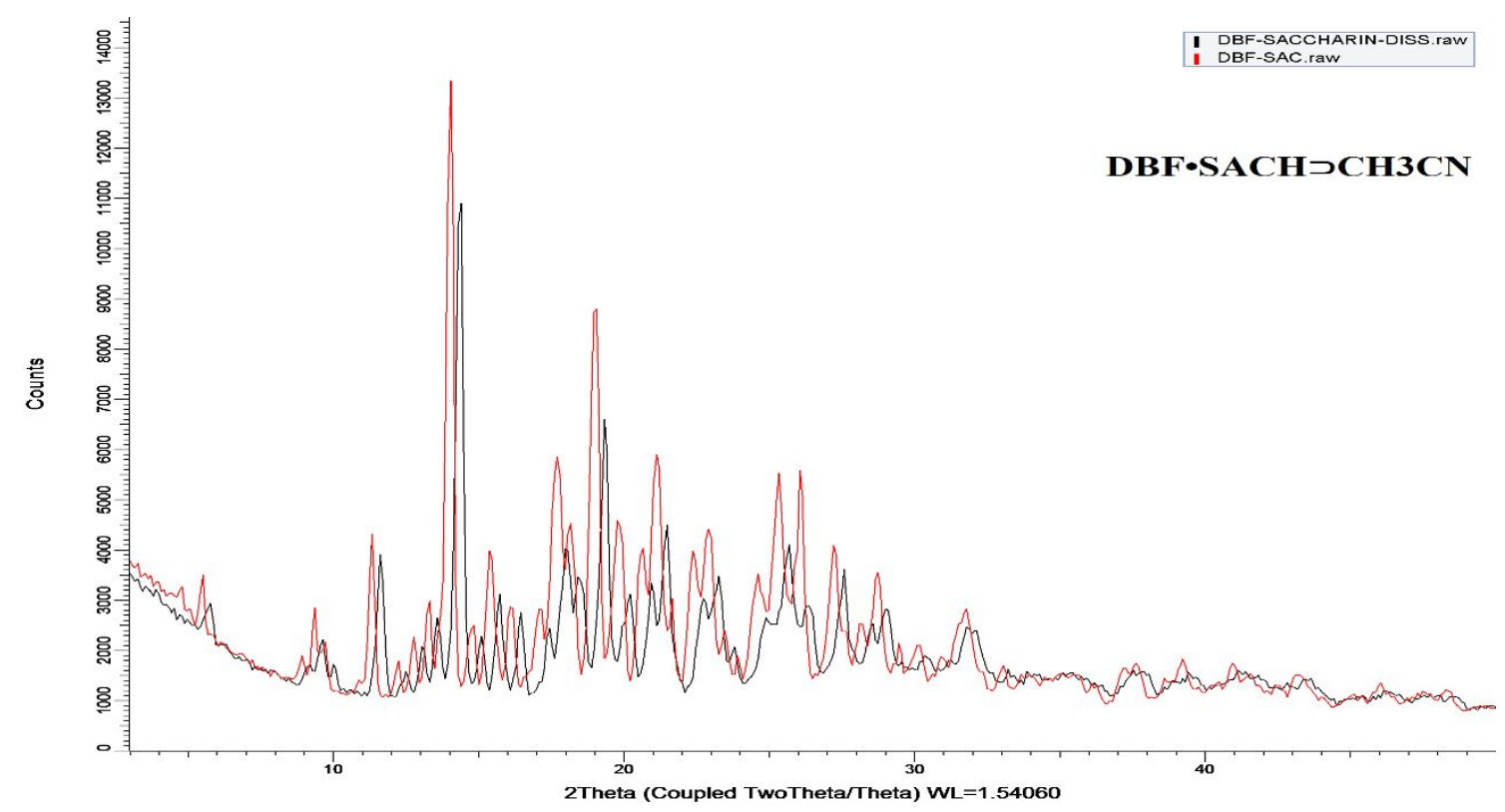

Figure S15. Overlay of PXRD patterns of DBF•SACHدCH $\mathbf{C H}_{3} \mathbf{C N}$ salt at the end of dissolution experiment (for $8 \mathrm{~h}$ ) in $\mathrm{pH} 1.2 \mathrm{HCl}$ buffer (black) matched with the PXRD pattern of $\mathbf{D B F} \cdot \mathbf{S A C H} \supset \mathrm{CH}_{3} \mathbf{C N}$ salt (red) collected before dissolution experiment, indicating the phase stability.

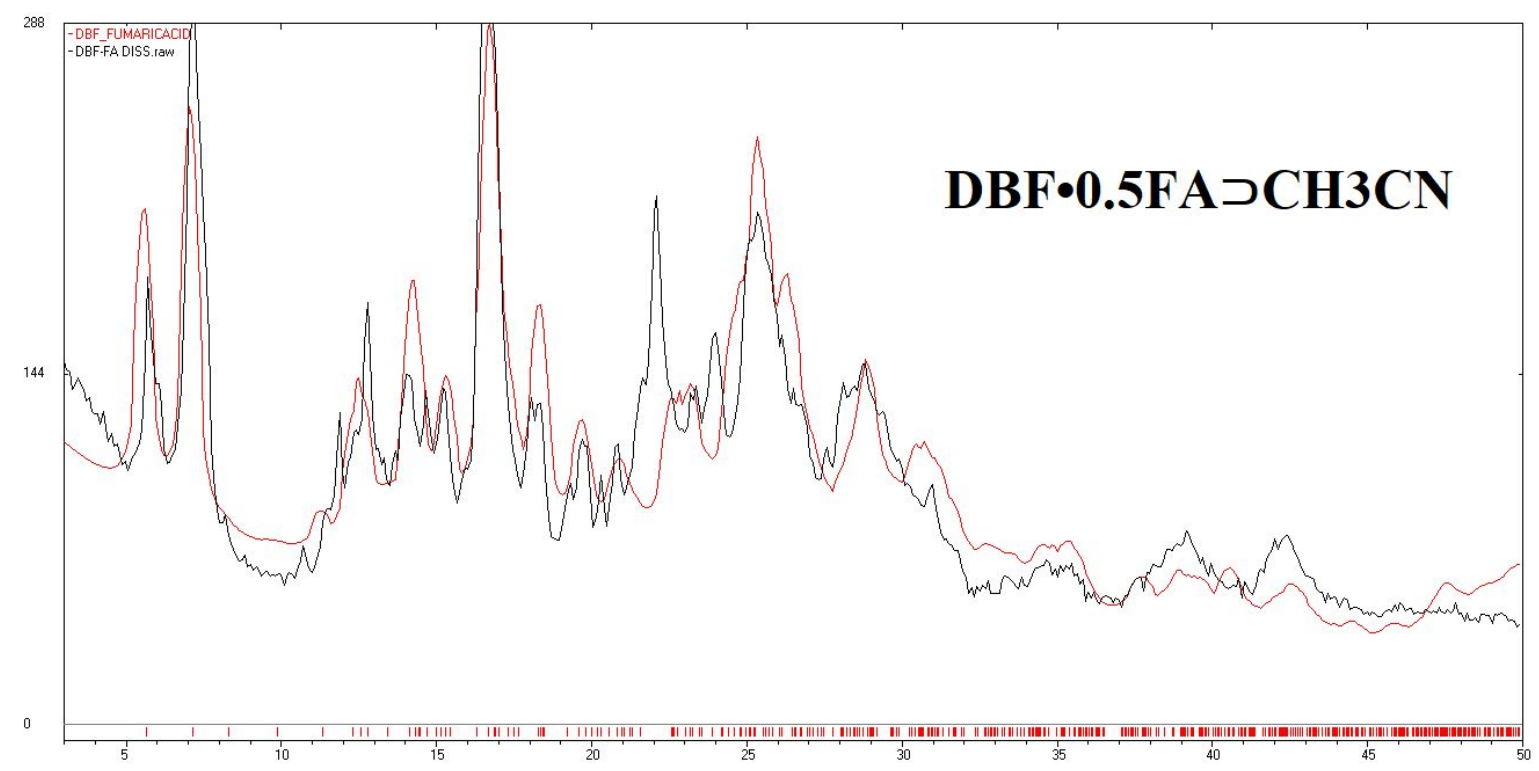

Figure S16. Overlay of PXRD patterns of DBF•0.5FA $\supset \mathrm{CH}_{3} \mathbf{C N}$ at the end of dissolution experiment (for $8 \mathrm{~h}$ ) in $\mathrm{pH} 1.2 \mathrm{HCl}$ buffer (black) matched with the calculated XRD pattern of $\mathrm{DBF} \bullet \mathbf{0 . 5 F A} \supset \mathrm{CH}_{3} \mathbf{C N}$ (red) indicating phase stability $(\mathrm{Rp}=17.00 \%$ and $\mathrm{Rwp}=21.40 \%)$. 


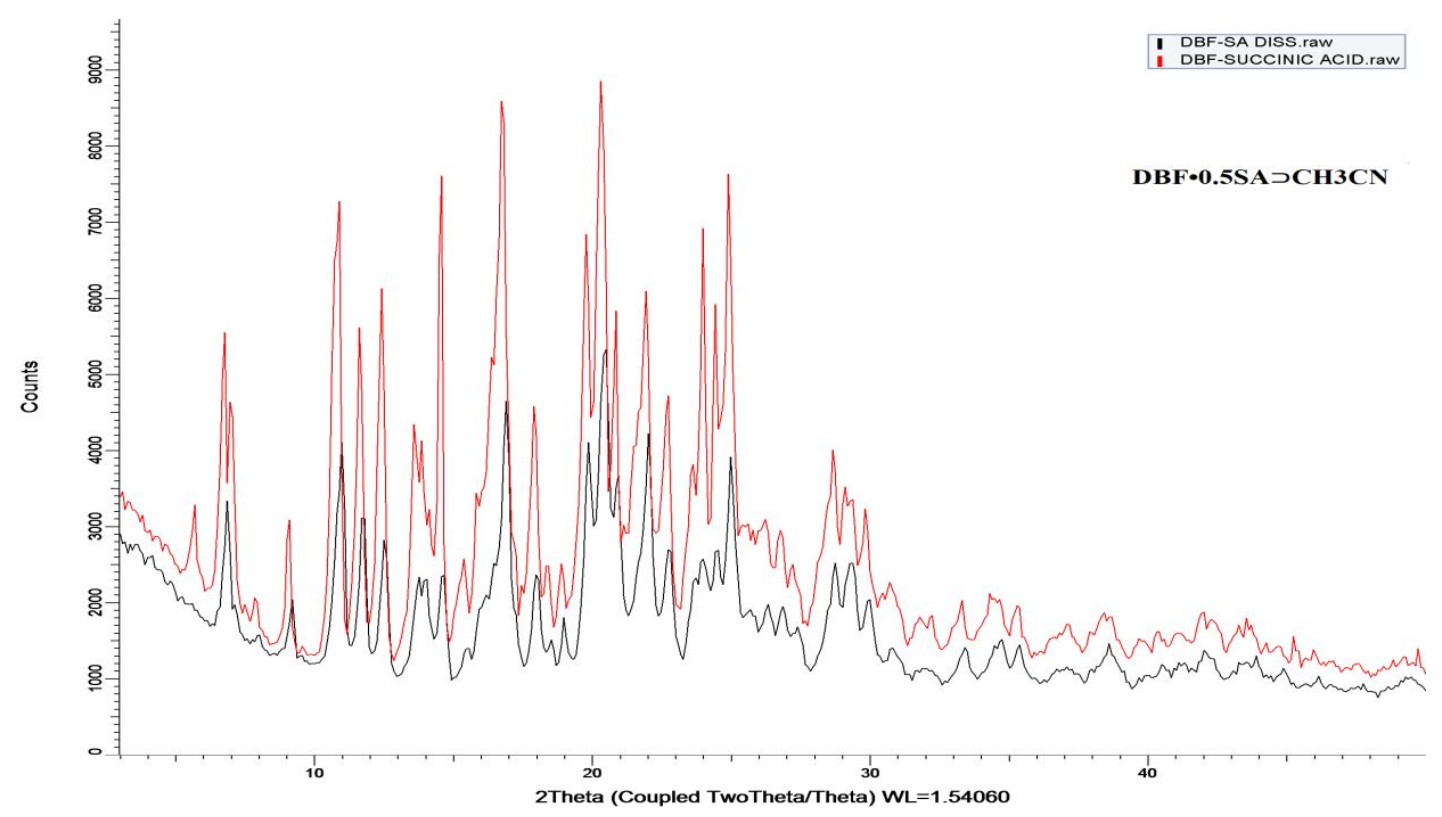

Figure S17. Overlay of PXRD patterns of DBF•0.5SA $\supset \mathrm{CH}_{3} \mathbf{C N}$ at the end of dissolution experiment in $\mathrm{pH} 1.2 \mathrm{HCl}$ buffer (8h black) matched with the PXRD pattern of DBF•0.5SA ${ } \mathrm{CH}_{3} \mathbf{C N}$ (red) collected before dissolution experiment, indicating phase stability.

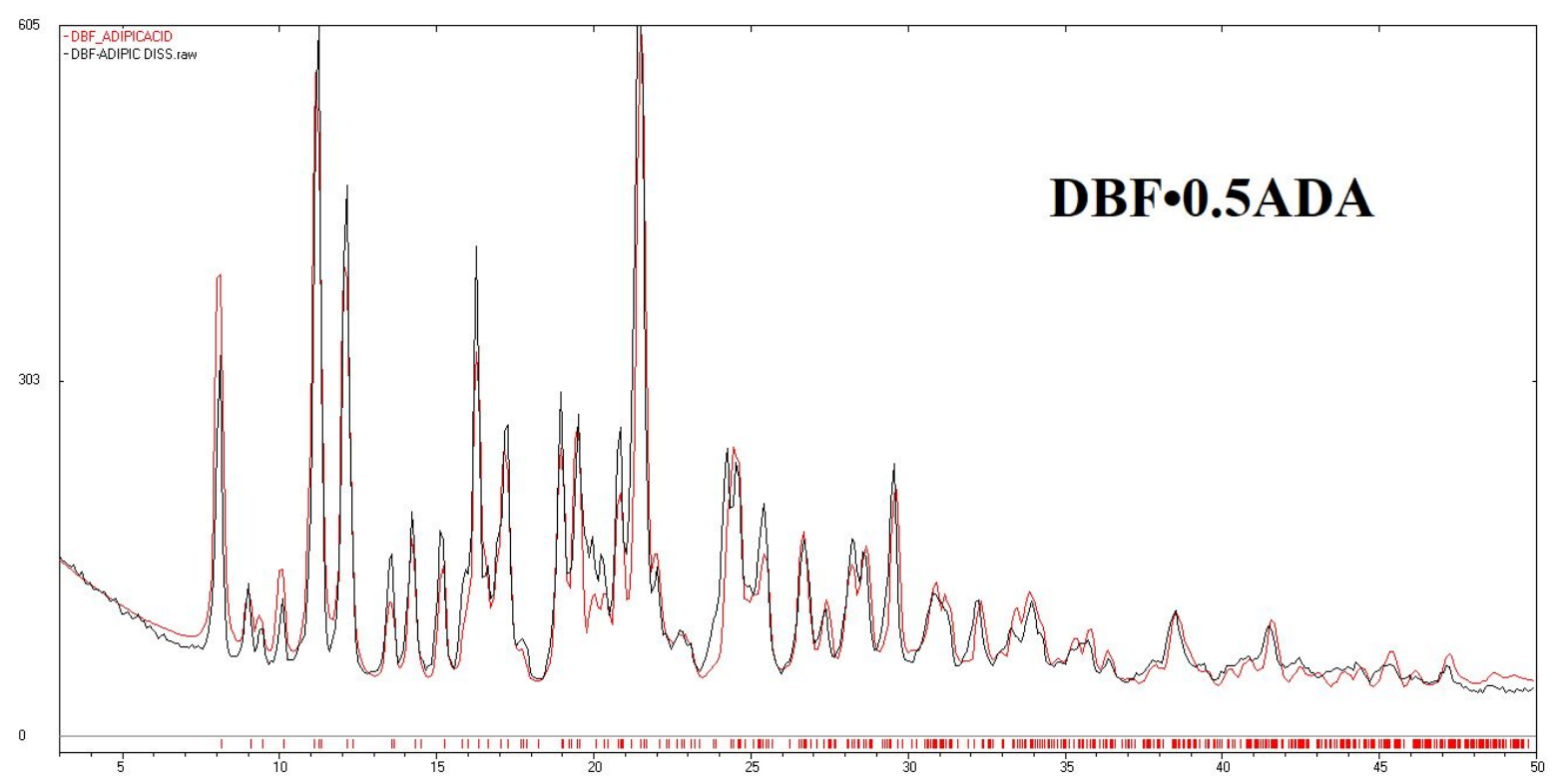

Figure S18. Overlay of PXRD patterns of DBF•0.5ADA at the end of dissolution experiment (for $8 \mathrm{~h}$ ) in $\mathrm{pH} 1.2 \mathrm{HCl}$ buffer (black) matched with the calculated XRD pattern of DBF•0.5ADA (red) indicating phase stability $(\mathrm{Rp}=15.38 \%$ and $\mathrm{Rwp}=19.20 \%)$. 


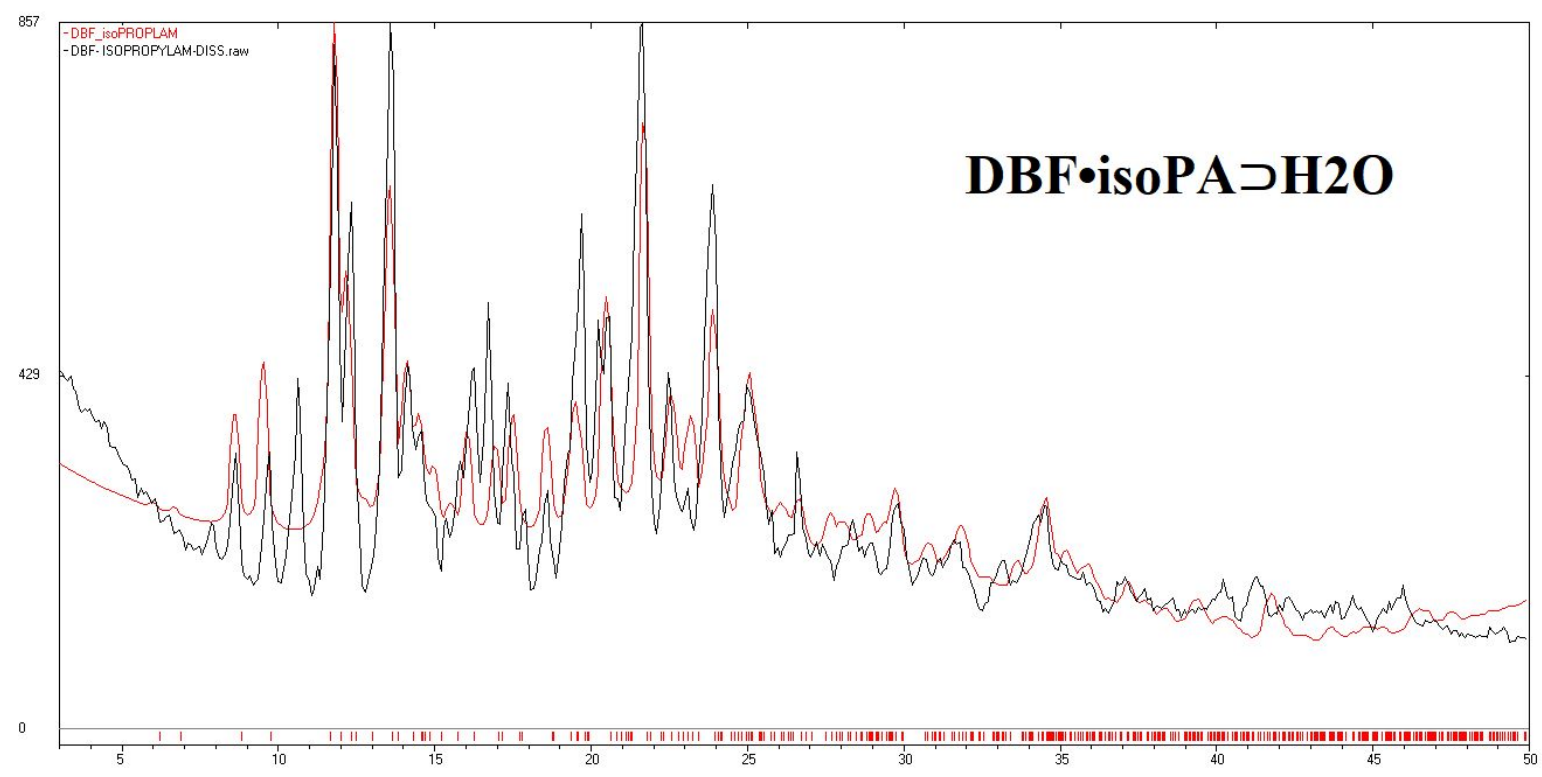

Figure S19. Overlay of PXRD patterns of DBF•isoPAつ $\mathrm{H}_{2} \mathrm{O}$ at the end of dissolution experiment (for $8 \mathrm{~h}$ ) in $\mathrm{pH} 1.2 \mathrm{HCl}$ buffer (black) matched with the calculated XRD pattern of DBF•isoPA $\supset H_{2} \mathbf{O}$ (red) indicating phase stability $(\mathrm{Rp}=17.69 \%$ and $\mathrm{Rwp}=22.48 \%)$.

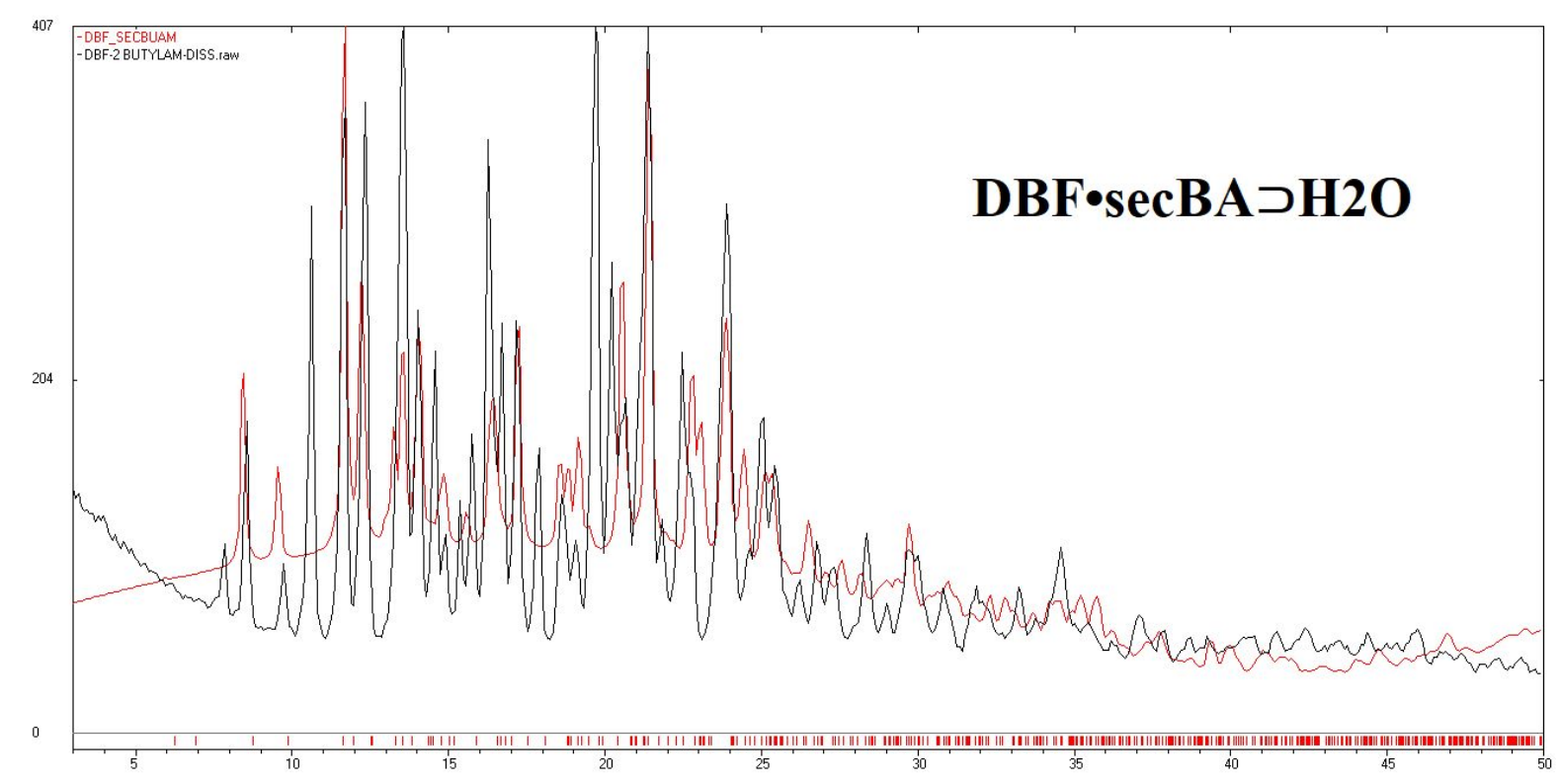

Figure S20. Overlay of PXRD patterns of DBF•secBAD $\mathrm{H}_{2} \mathbf{O}$ at the end of dissolution experiment (for $8 \mathrm{~h}$ ) in $\mathrm{pH} 1.2 \mathrm{HCl}$ buffer (black) matched with the calculated XRD pattern of DBF•secBA $\supset H_{2} \mathrm{O}$ (red) indicating phase stability $(\mathrm{Rp}=26.38 \%$ and $\mathrm{Rwp}=33.64 \%)$. 


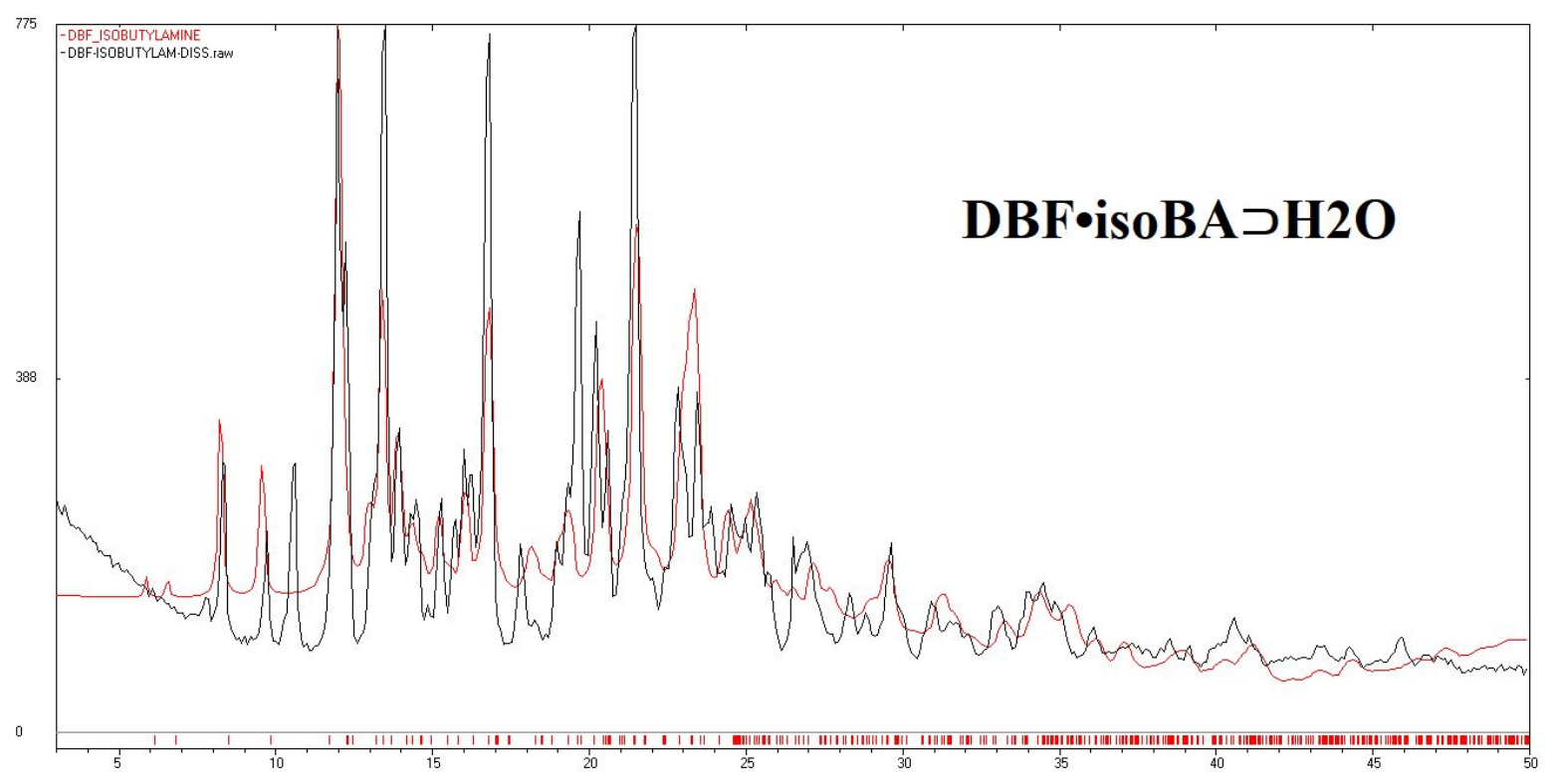

Figure S21. Overlay of PXRD patterns of DBF•isoBA $\supset \mathbf{H}_{2} \mathbf{O}$ at the end of dissolution experiment (for $8 \mathrm{~h}$ ) in $\mathrm{pH} 1.2 \mathrm{HCl}$ buffer (black) matched with the calculated XRD pattern of DBF•isoBA $\supset H_{2} \mathbf{O}$ (red) indicating phase stability (Rp22.53\% and Rwp28.53\%).

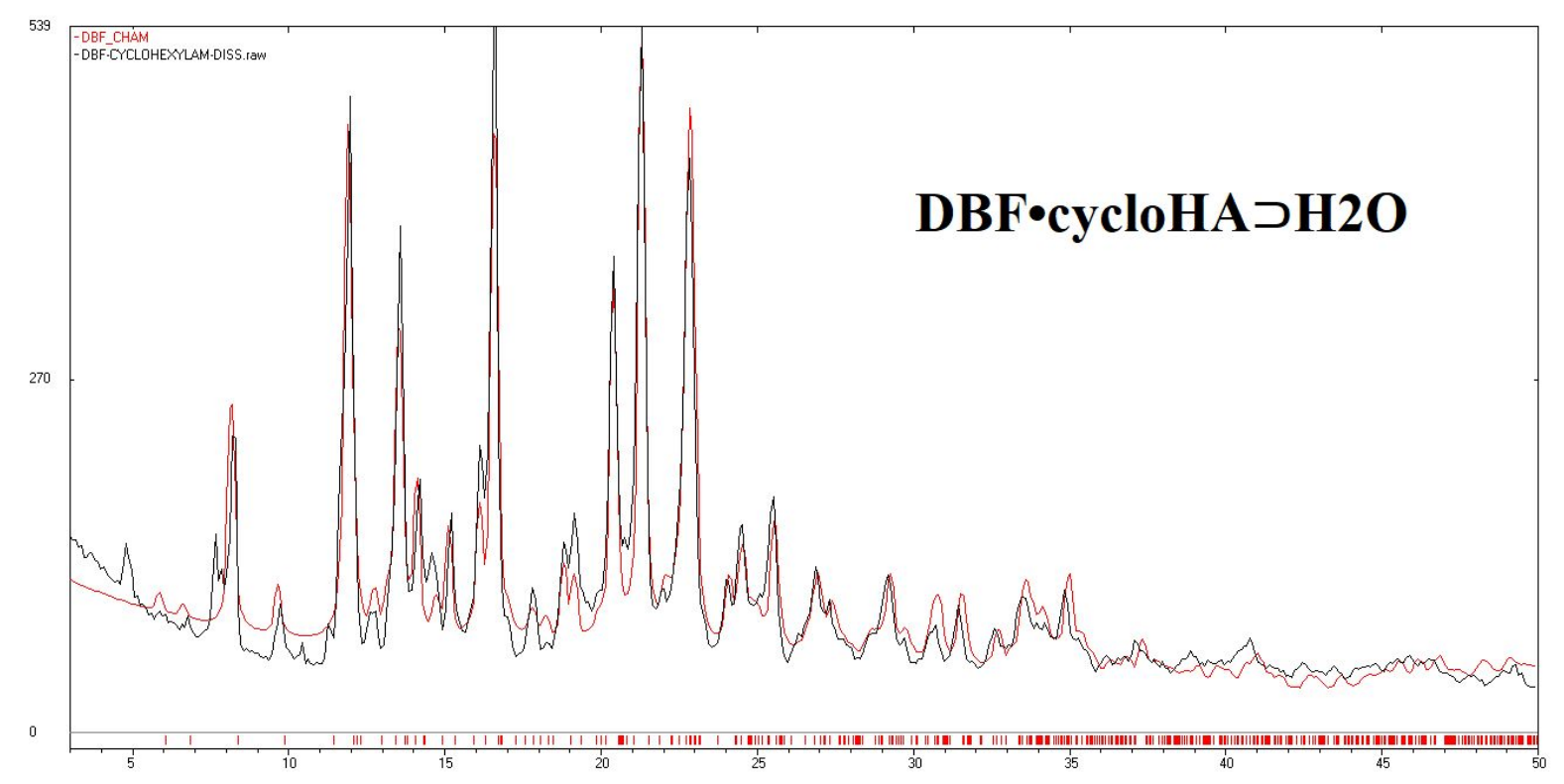

Figure S22. Overlay of PXRD patterns of DBF•cycloHA $\supset \mathrm{H}_{2} \mathrm{O}$ at the end of dissolution experiment (for $8 \mathrm{~h}$ ) in $\mathrm{pH} 1.2 \mathrm{HCl}$ buffer (black) matched with the calculated XRD pattern of DBF•cycloHA $\supset \mathrm{H}_{2} \mathrm{O}$ (red) indicating phase stability $(\mathrm{Rp}=16.52 \%$ and $\mathrm{Rwp}=20.40 \%)$. 


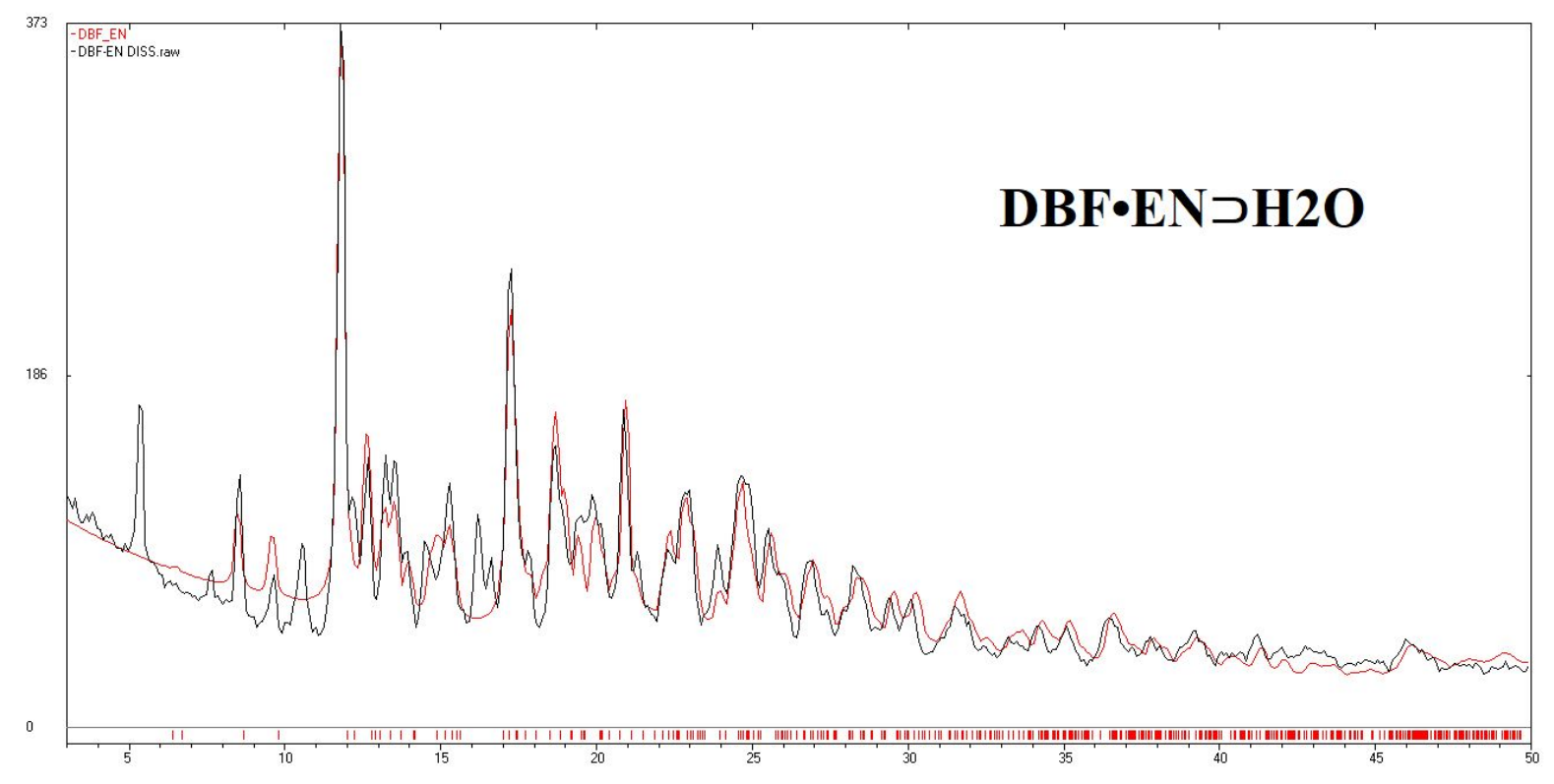

Figure S23. Overlay of PXRD patterns of $\mathbf{D B F} \cdot \mathbf{E N} \supset \mathrm{H}_{2} \mathbf{O}$ at the end of dissolution experiment (for $8 \mathrm{~h}$ ) in $\mathrm{pH} 1.2 \mathrm{HCl}$ buffer (black) matched with the calculated XRD pattern of DBF•EN $\supset \mathrm{H}_{2} \mathrm{O}$ (red) indicating phase stability $(\mathrm{Rp}=12.72 \%$ and $\mathrm{Rwp}=16.26 \%)$.

1. The new solid form peaks observed in several cases at the end of dissolution experiment $(24 \mathrm{~h})$ have not yet been fully characterized in this study. There are peaks in PXRD at $2 \theta$ values corresponding to DBF monohydrate but the experimental diffraction pattern is complex and there are other phases visible as well (unpublished results).

2. The high Rp and Rwp values of $15-20 \%$ is not a serious concern in the PXRD overlay plots, since these value are not correlated directly with the goodness of overlap between the calculated and the experimental powder XRD line pattern. A good visual judgement is the best way to ascertain a proper fit.

Toby, R. H. R factors in Rietveld analysis: How good is good enough? Powder Diffraction, 2006, 21, 67-70. 


\section{Differential Scanning Calorimetry (DSC) data}

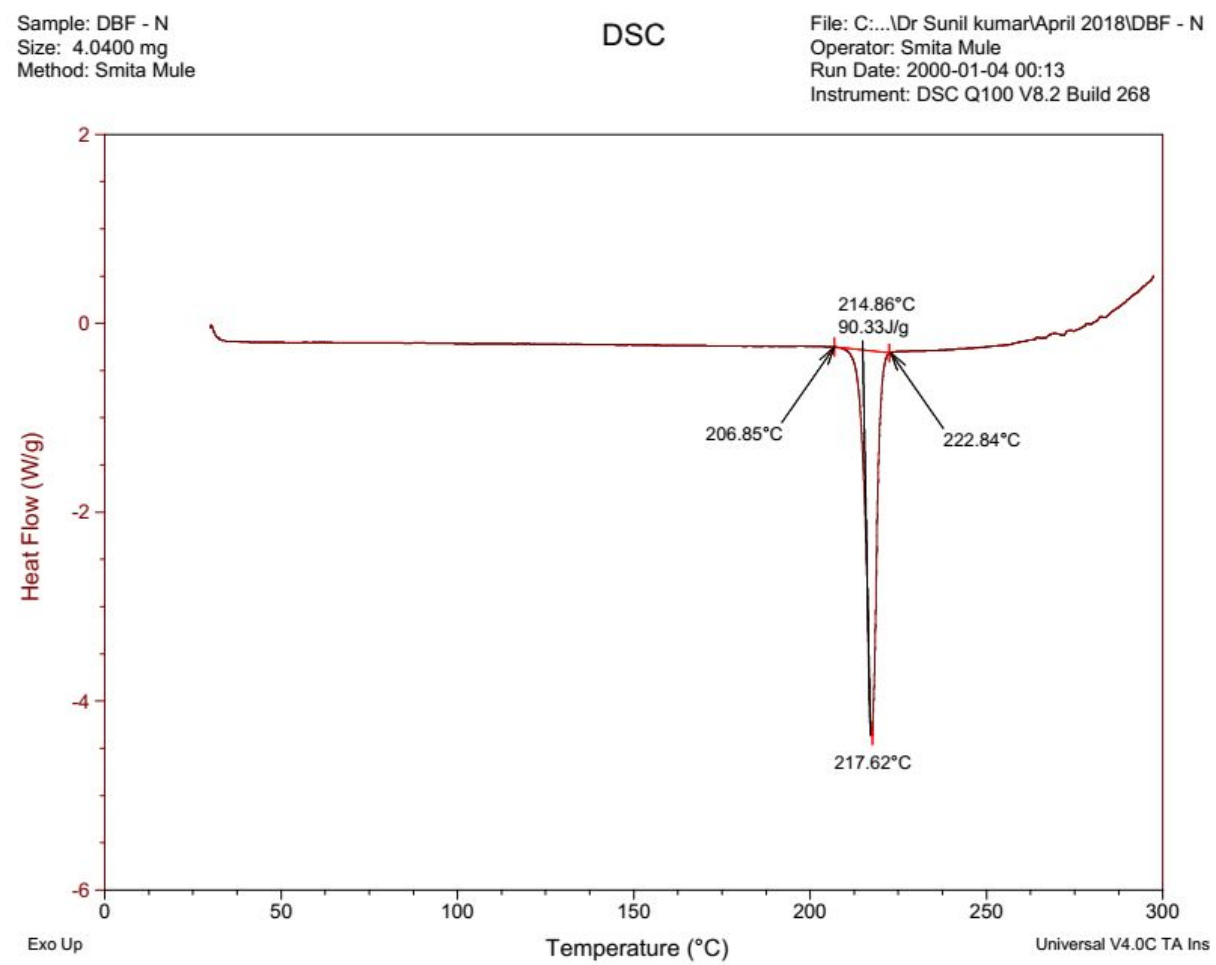

Figure S24. DSC thermogram of neutral DBF.

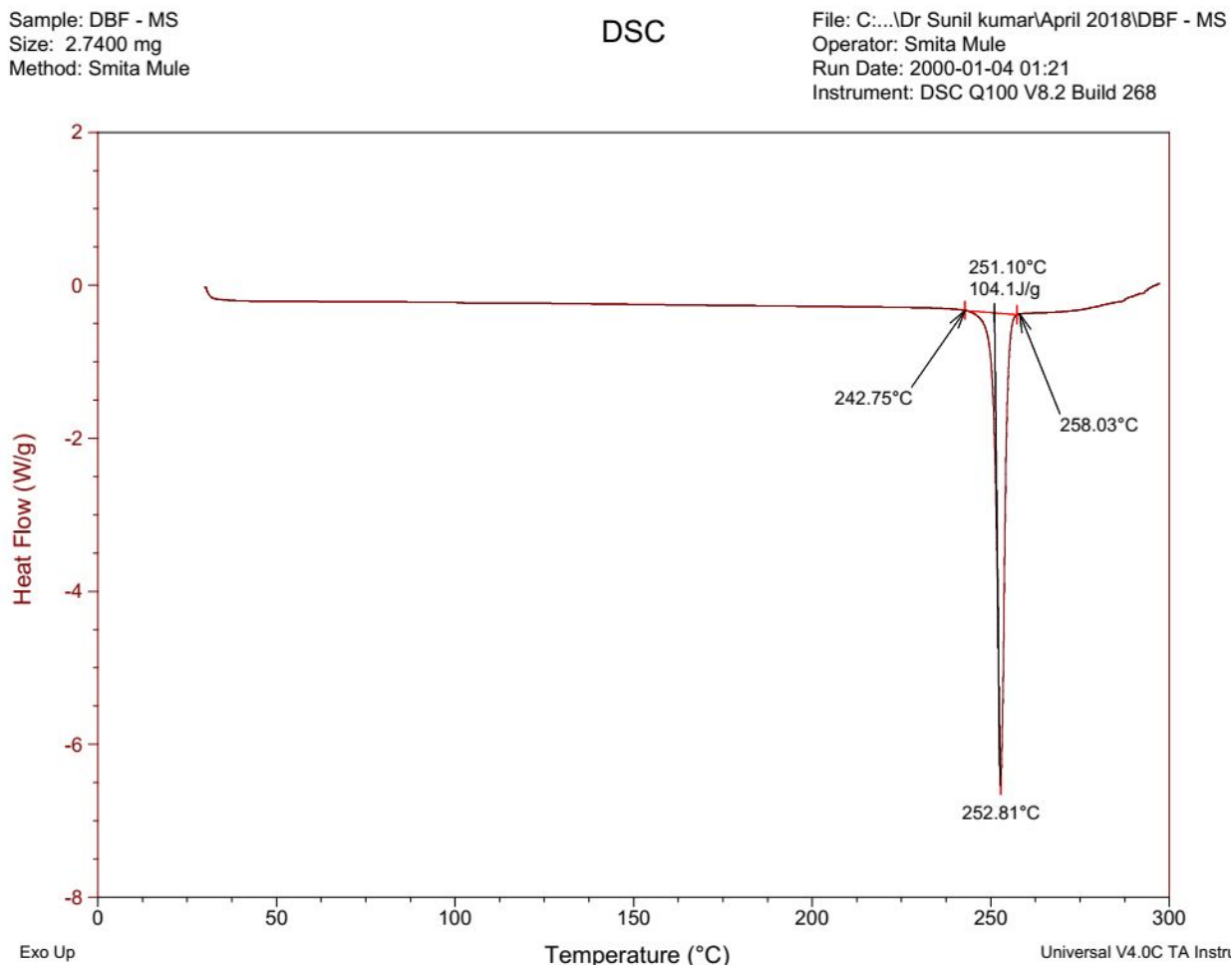

Figure S25. DSC thermogram of DBF $\bullet$ MS salt. 


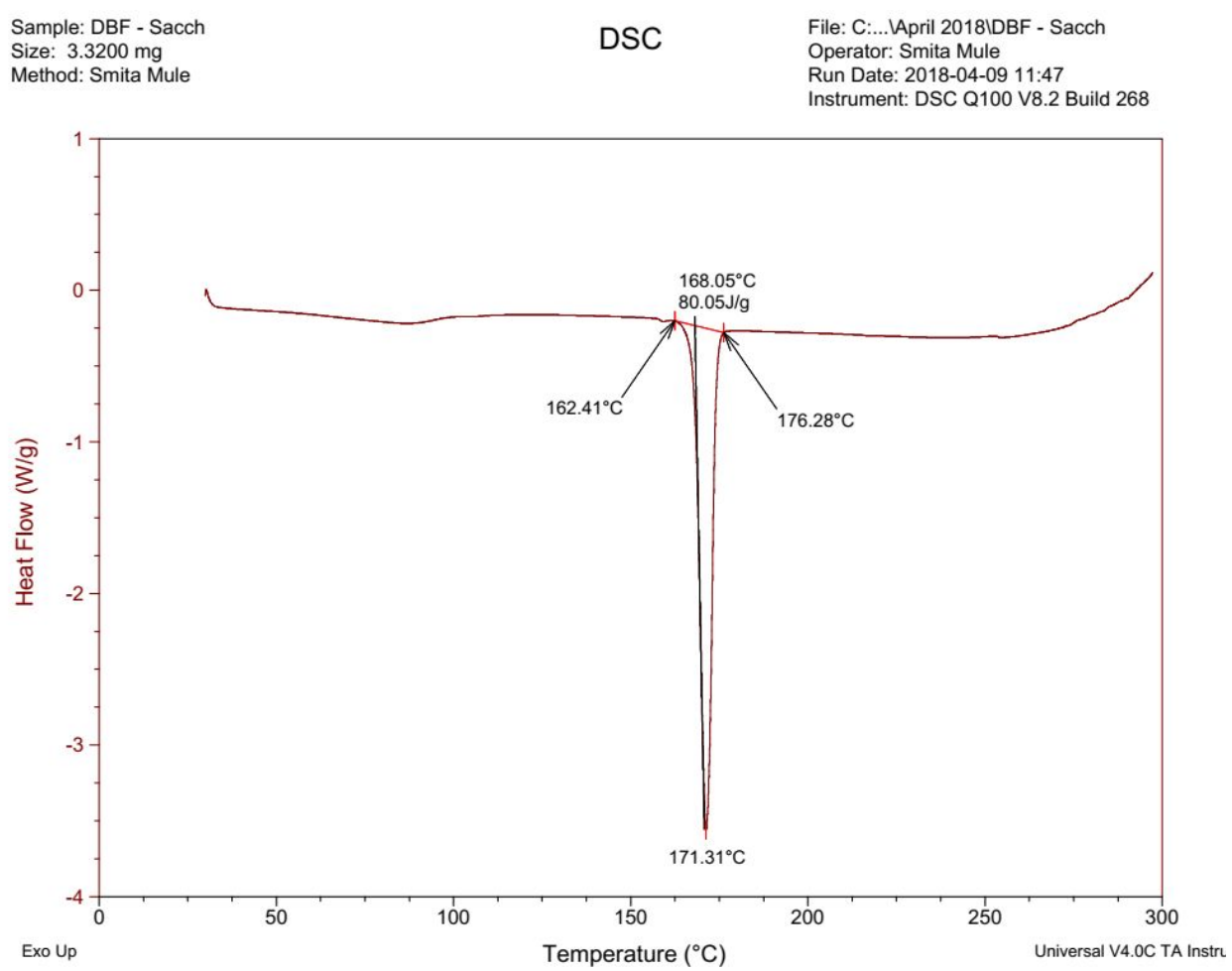

Figure S26. DSC thermogram of DBF•SACHدCH${ }_{3} \mathbf{C N}$.

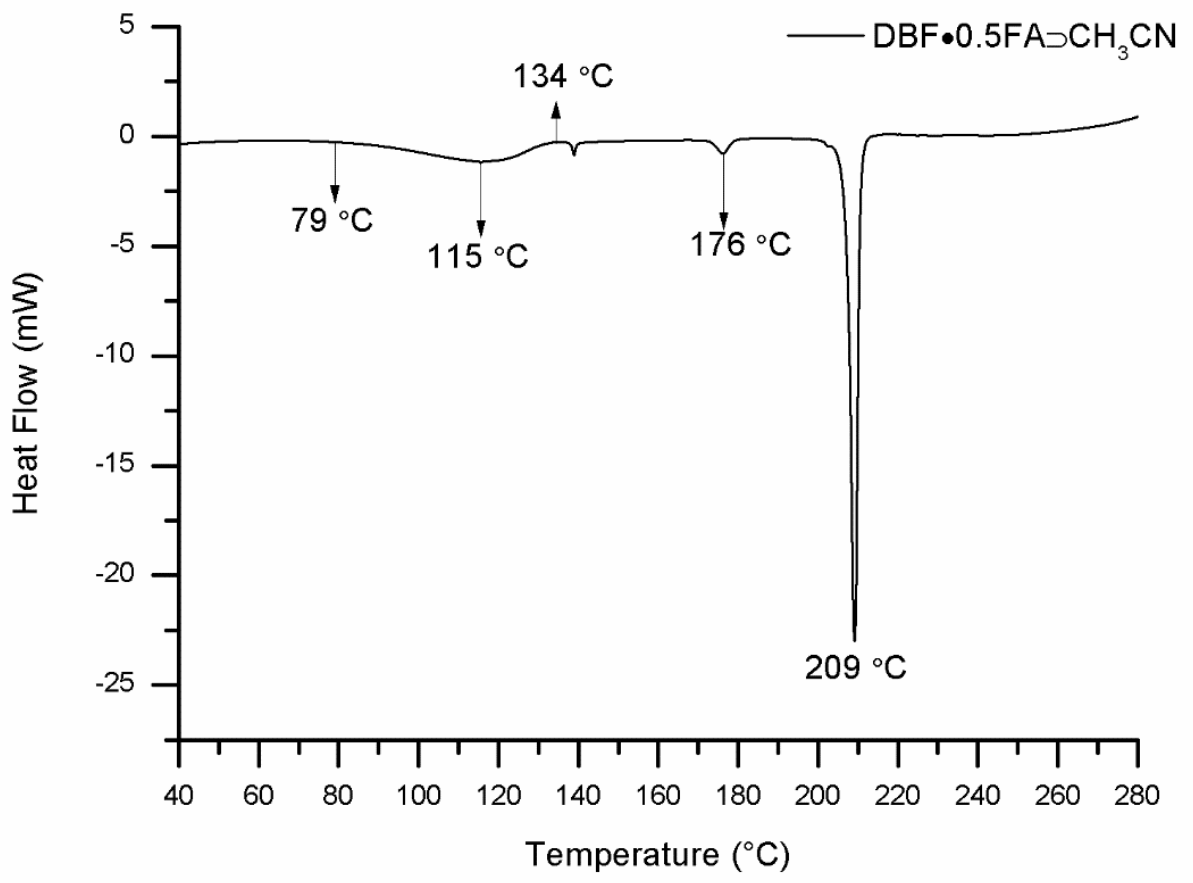

Figure S27. DSC thermogram of DBF• $0.5 F A \supset C_{3} \mathbf{C N}$. 


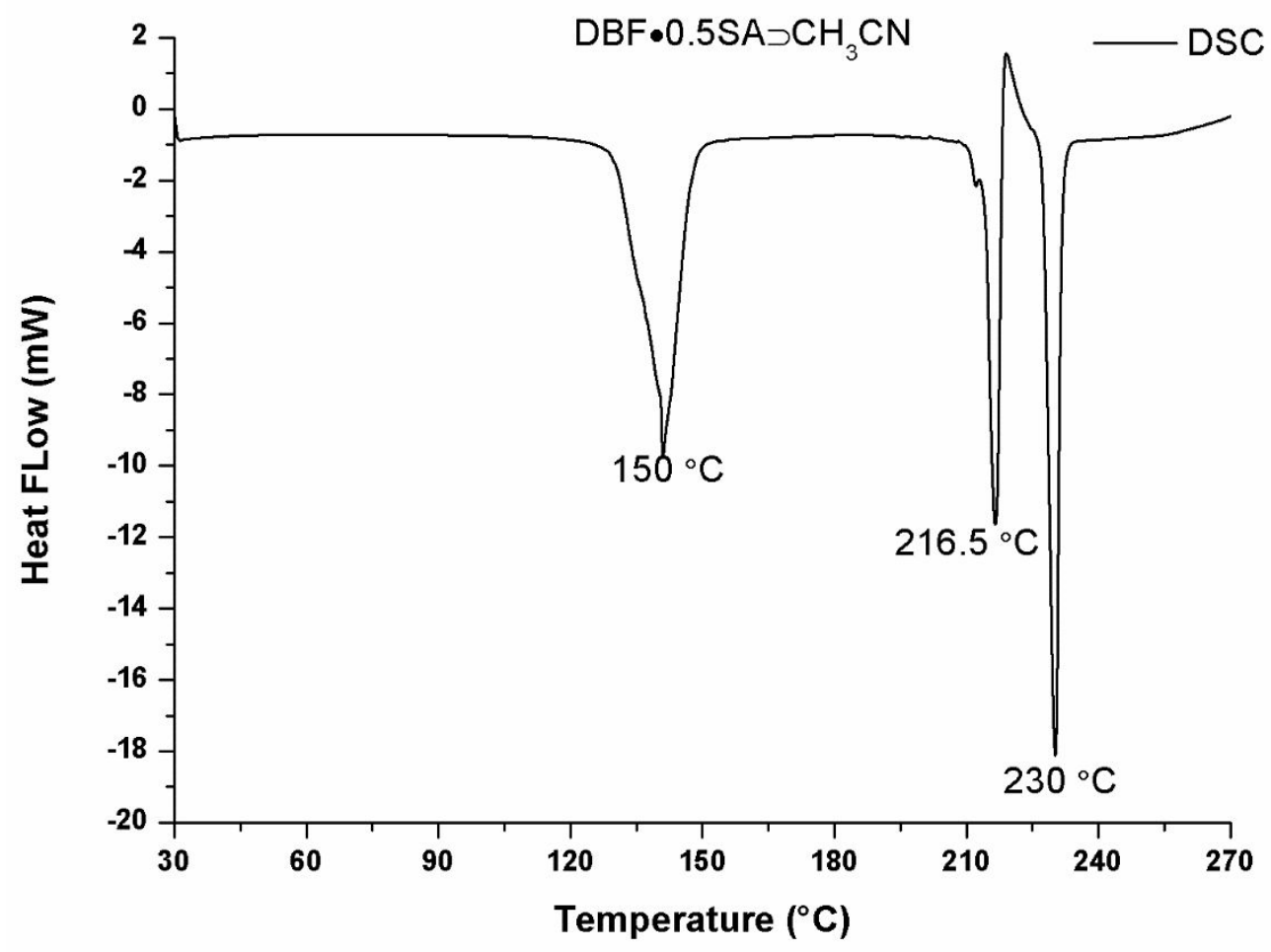

Figure S28. DSC thermogram of DBF•0.5SA $\supset \mathrm{CH}_{3} \mathrm{CN}$.

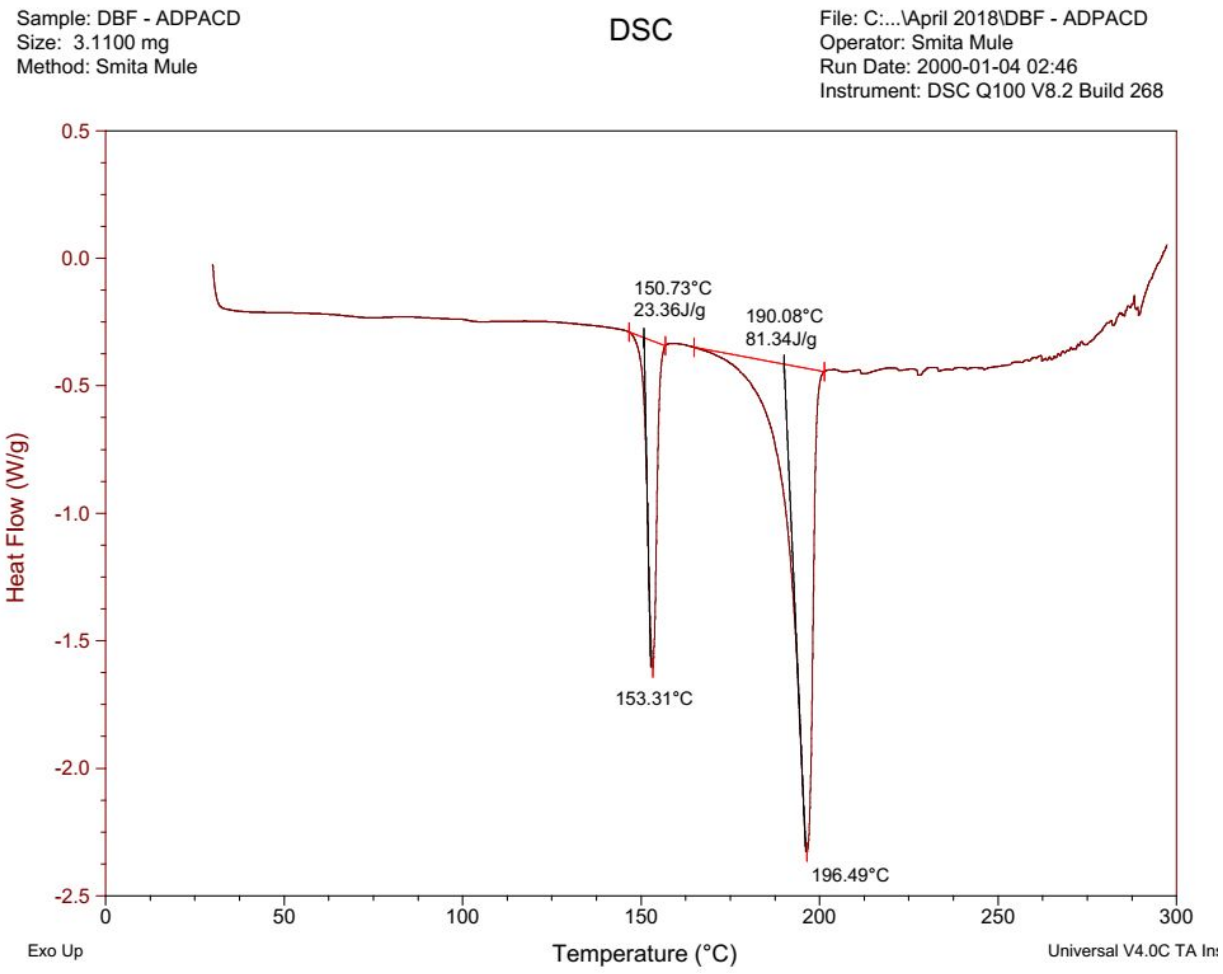

Figure S29. DSC thermogram of DBF•0.5ADA. 


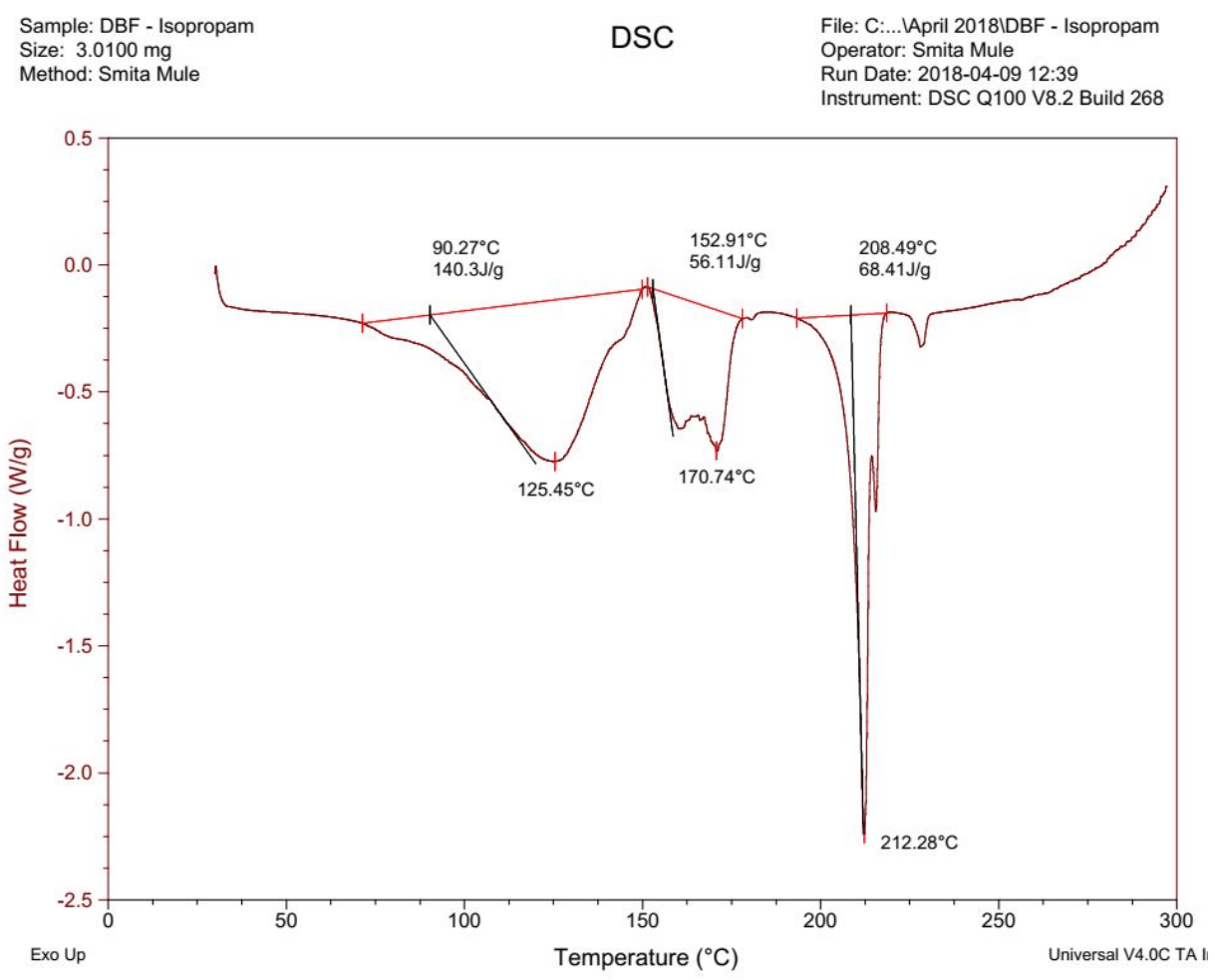

Figure S30. DSC thermogram of DBF•isoPA $\supset \mathrm{H}_{2} \mathrm{O}$.

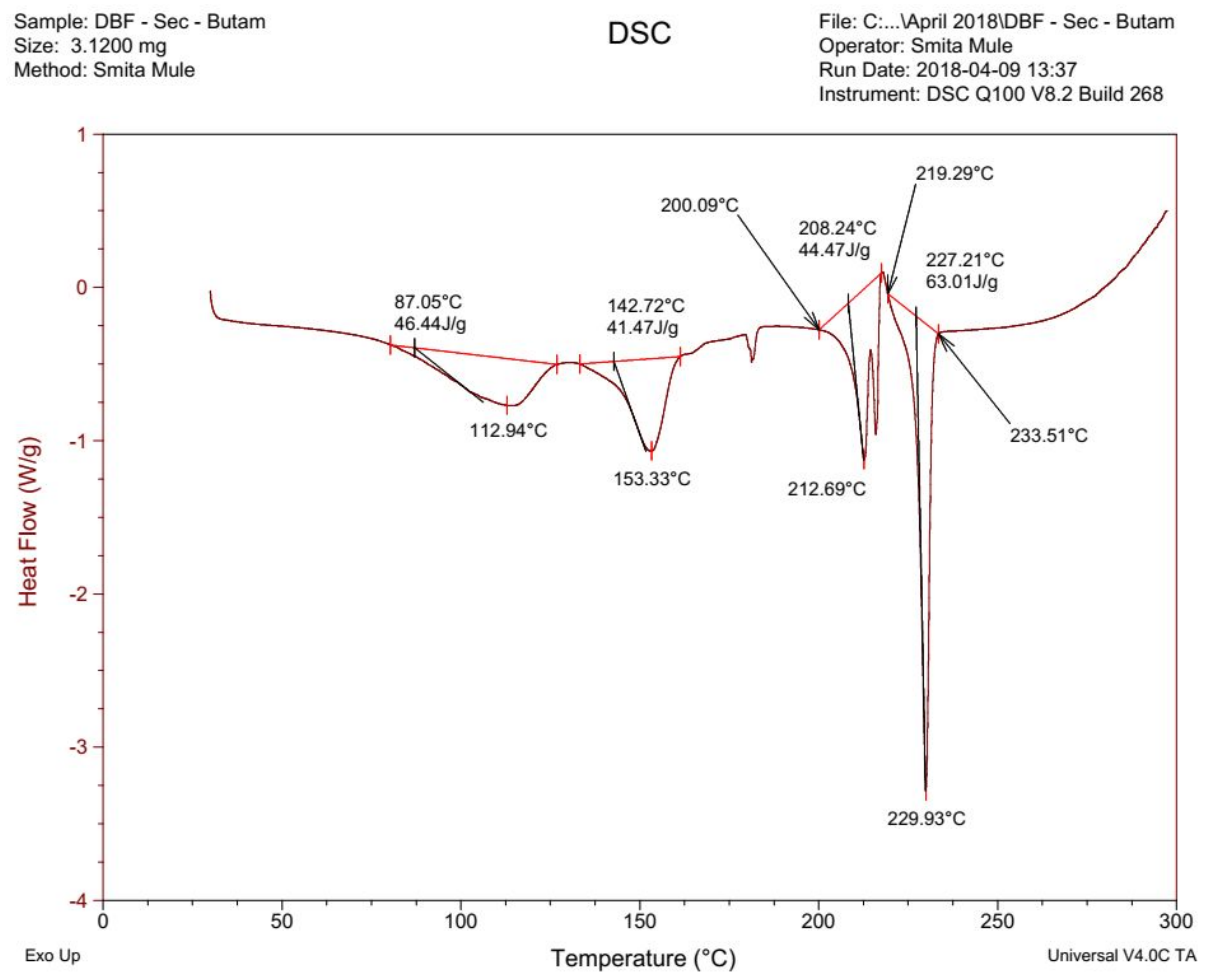

Figure S31. DSC thermogram of DBF•secBA $\supset \mathrm{H}_{2} \mathrm{O}$. 


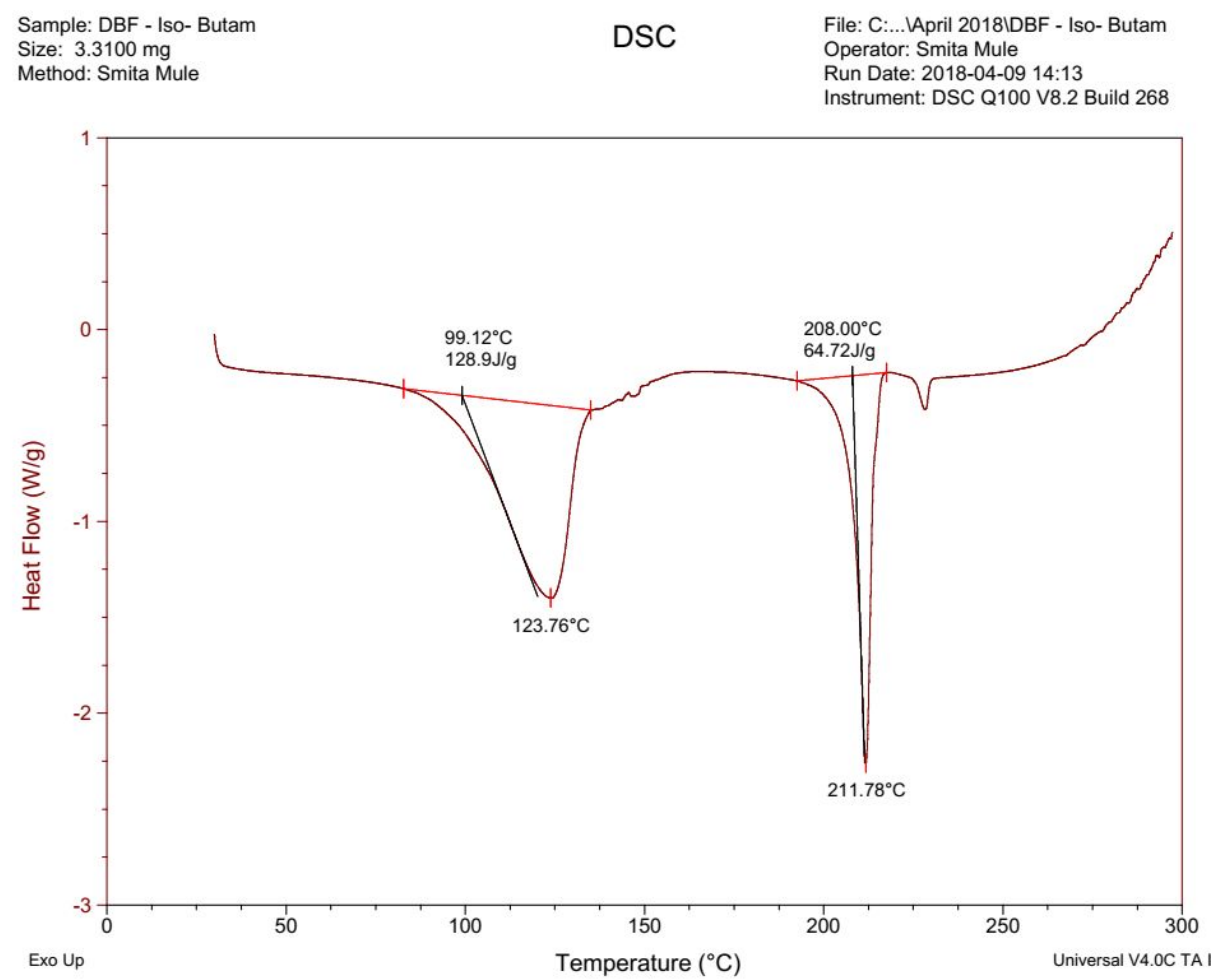

Figure S32. DSC thermogram of DBF•isoBA $\mathrm{SH}_{2} \mathrm{O}$.

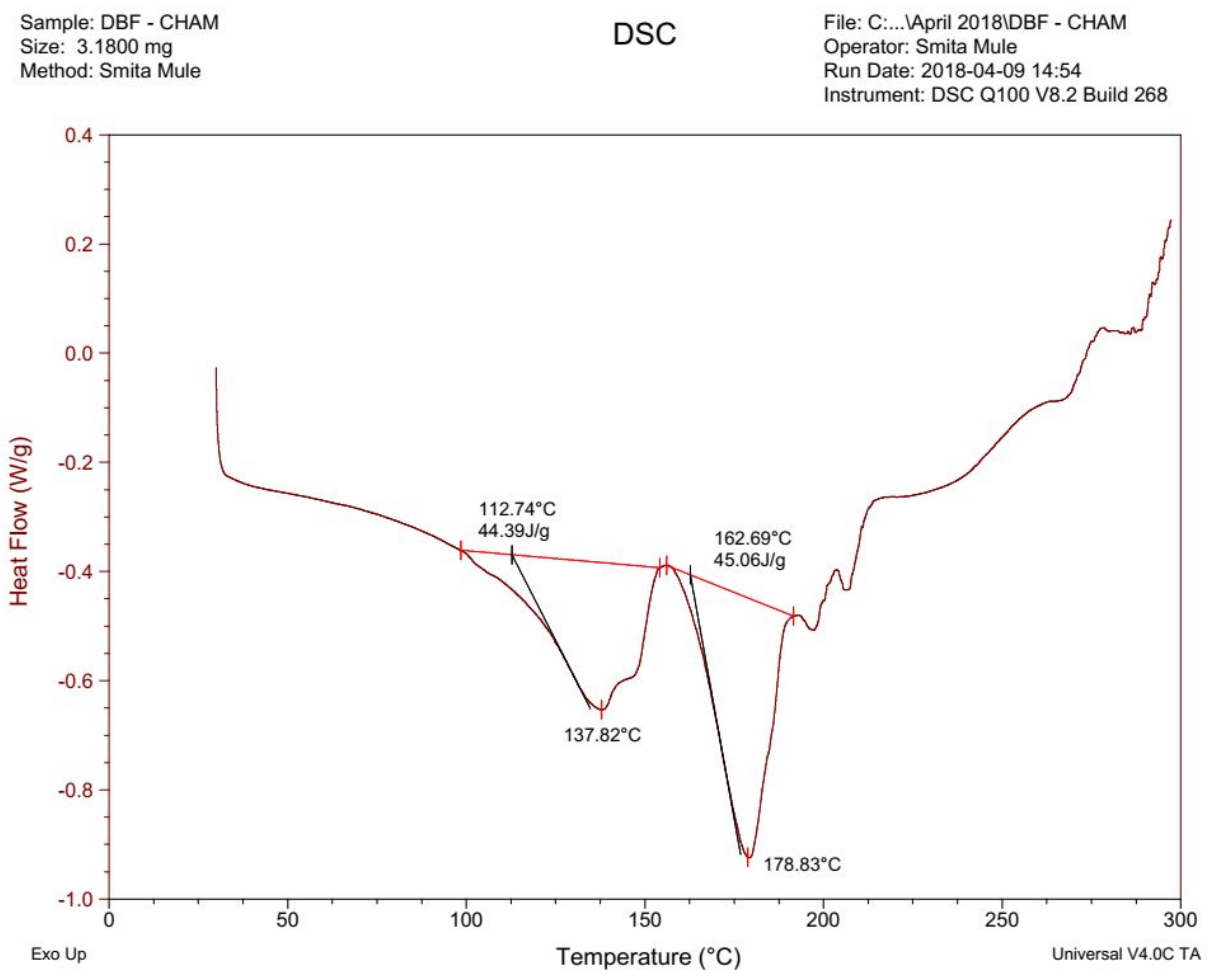

Figure S33. DSC thermogram of DBF•cycloHA $\supset \mathrm{H}_{2} \mathbf{O}$. 


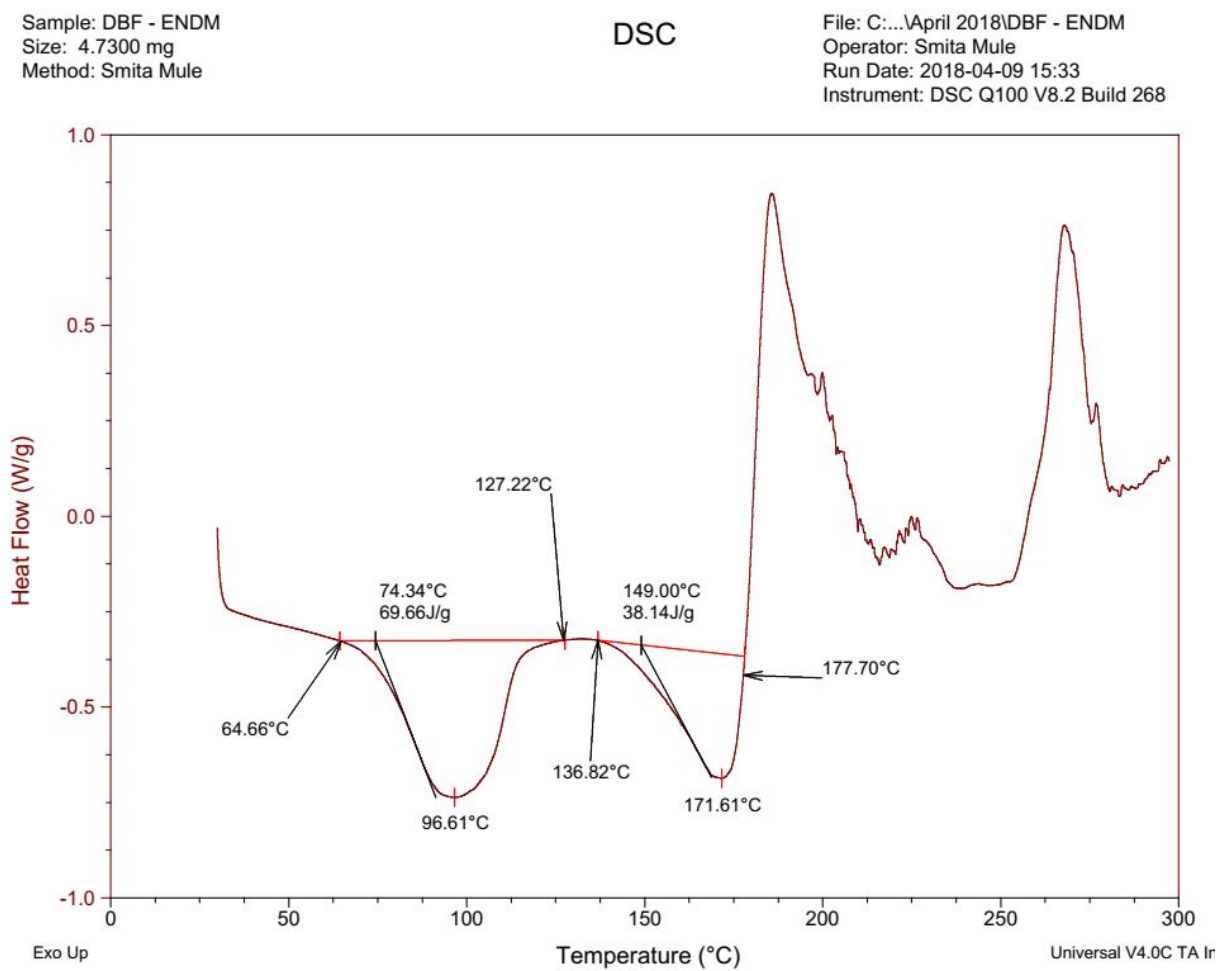

Figure S34. DSC thermogram of DBF•EN $\supset \mathrm{H}_{2} \mathbf{O}$. 
5. Thermal Gravimetric Analysis (TGA) data

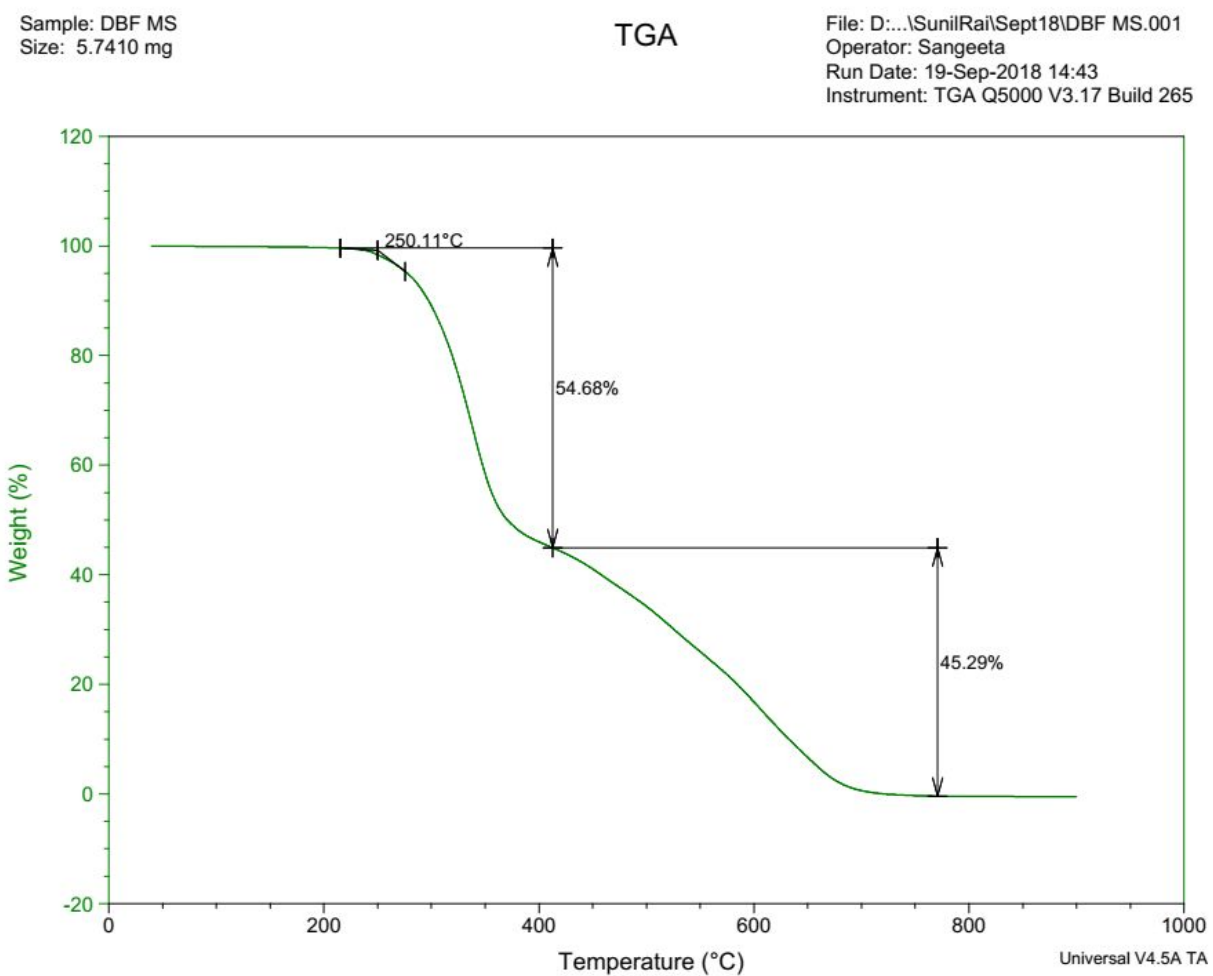

Figure S35. TGA thermogram of $\mathbf{D B F} \bullet \mathbf{M S}$.

Run Date: 18-Sep-2018 12:30

Instrument: TGA Q5000 V3.17 Build 265

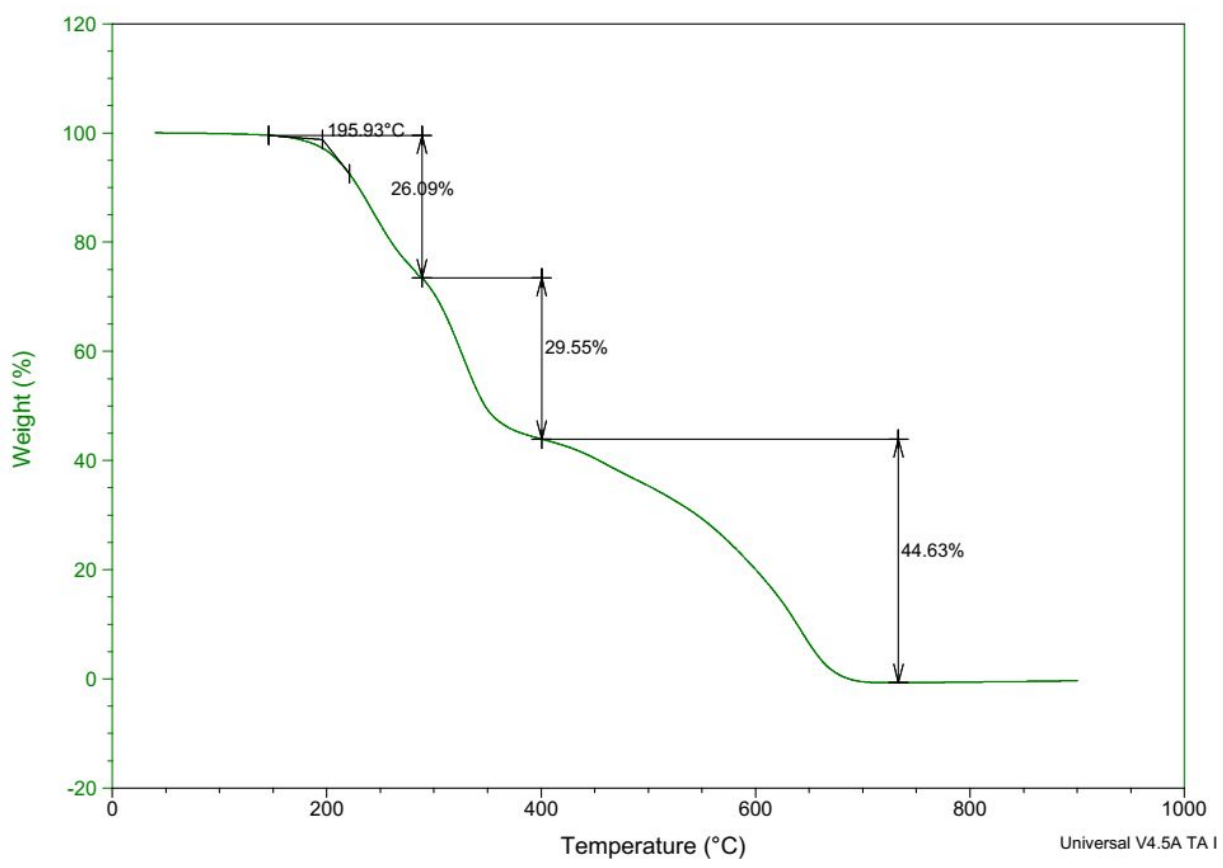

Figure S36. TGA thermogram of DBF•SACHدCH $\mathrm{CH}_{3} \mathrm{CN}$. 


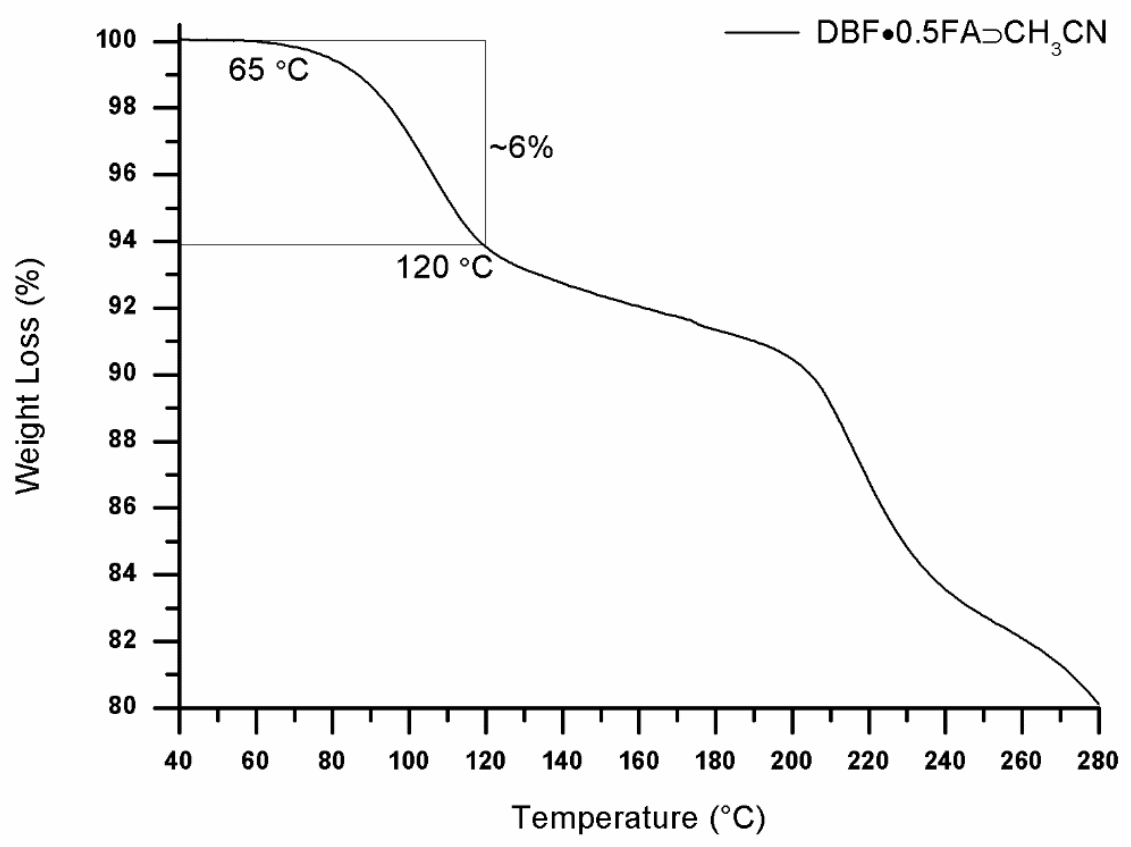

Figure S37. TGA thermogram of DBF•0.5FA $\supset \mathrm{CH}_{3} \mathrm{CN}$.

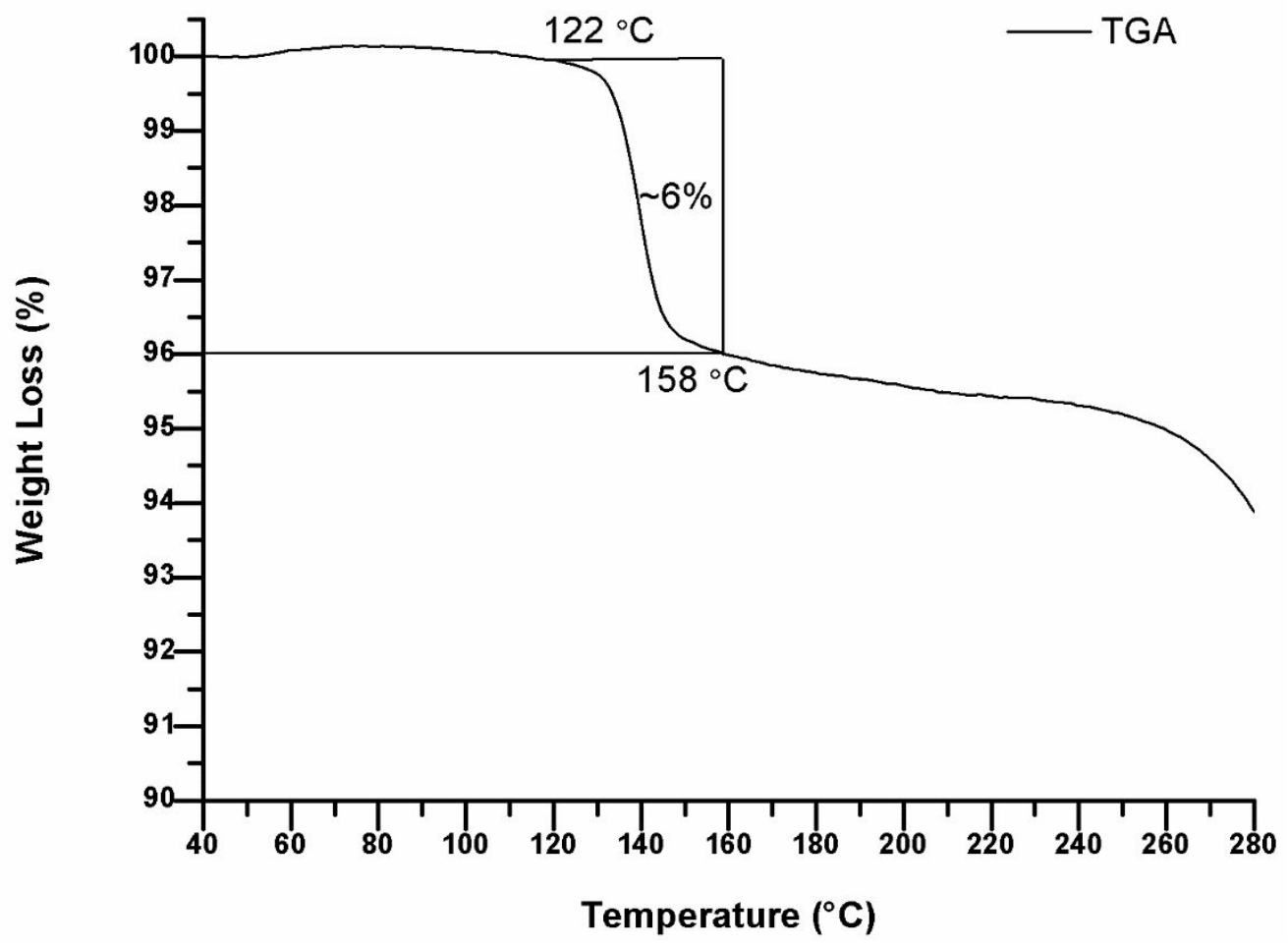

Figure S38. TGA thermogram of $\mathrm{DBF} \bullet \mathbf{0 . 5 S A} \supset \mathrm{CH}_{3} \mathrm{CN}$. 


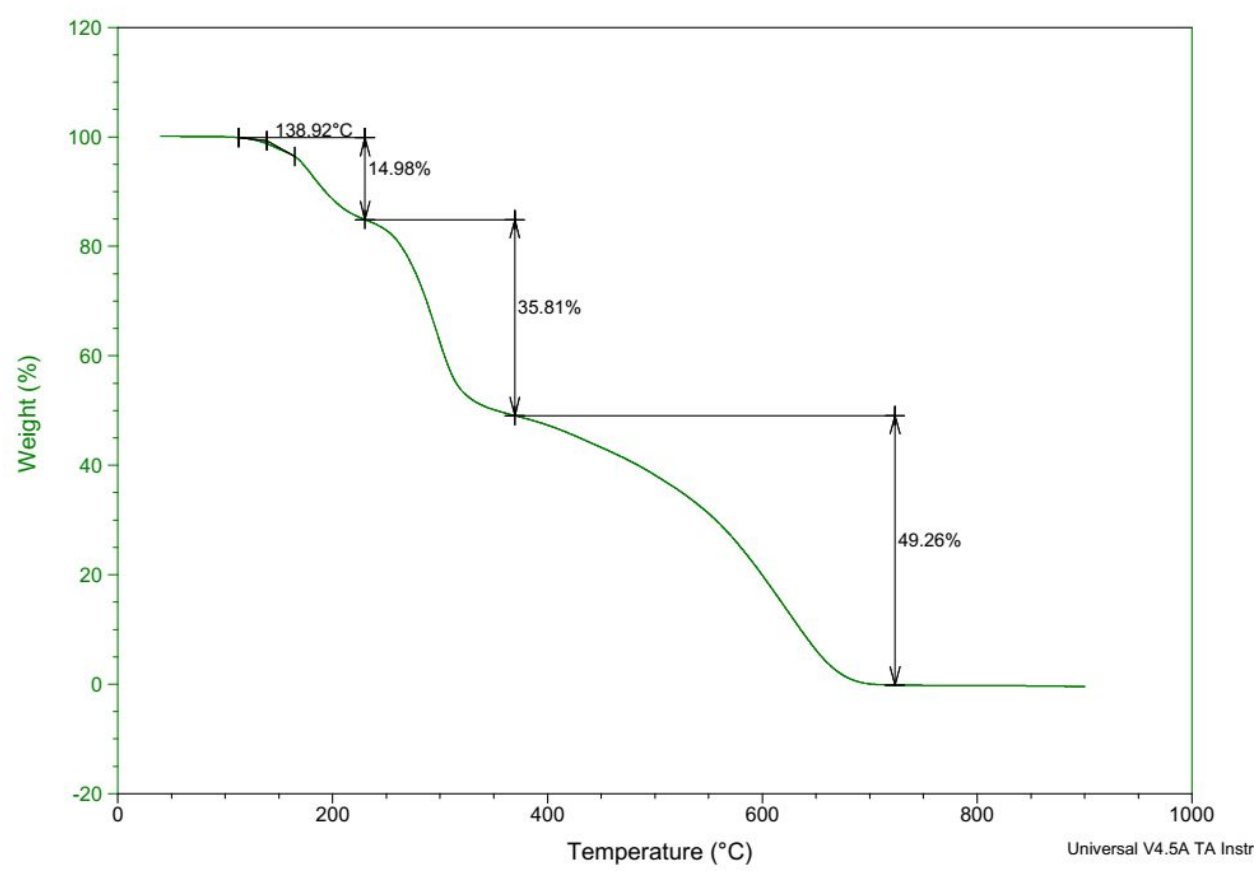

Figure S39. TGA thermogram of DBF•ADA.

Sample: DBF Isoprop 1:1 ACN Size: $5.7280 \mathrm{mg}$

TGA Operator: Sangeeta

Run Date: 30-Aug-2018 14:10

Instrument: TGA Q5000 V3.17 Build 265

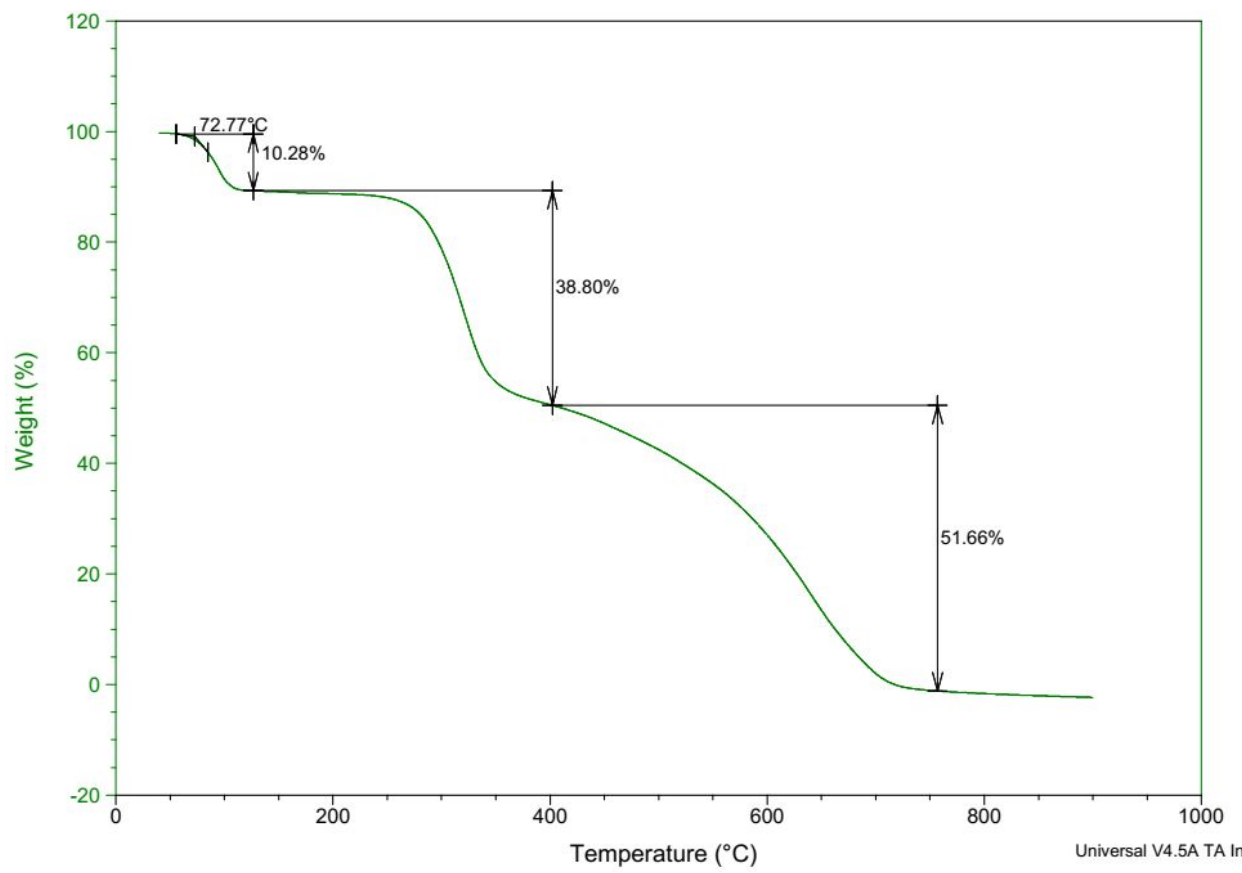

Figure S40. TGA thermogram of DBF•isoPA $\supset \mathrm{H}_{2} \mathrm{O}$. 
Run Date: 18-Sep-2018 14:51

Instrument: TGA Q5000 V3.17 Build 265

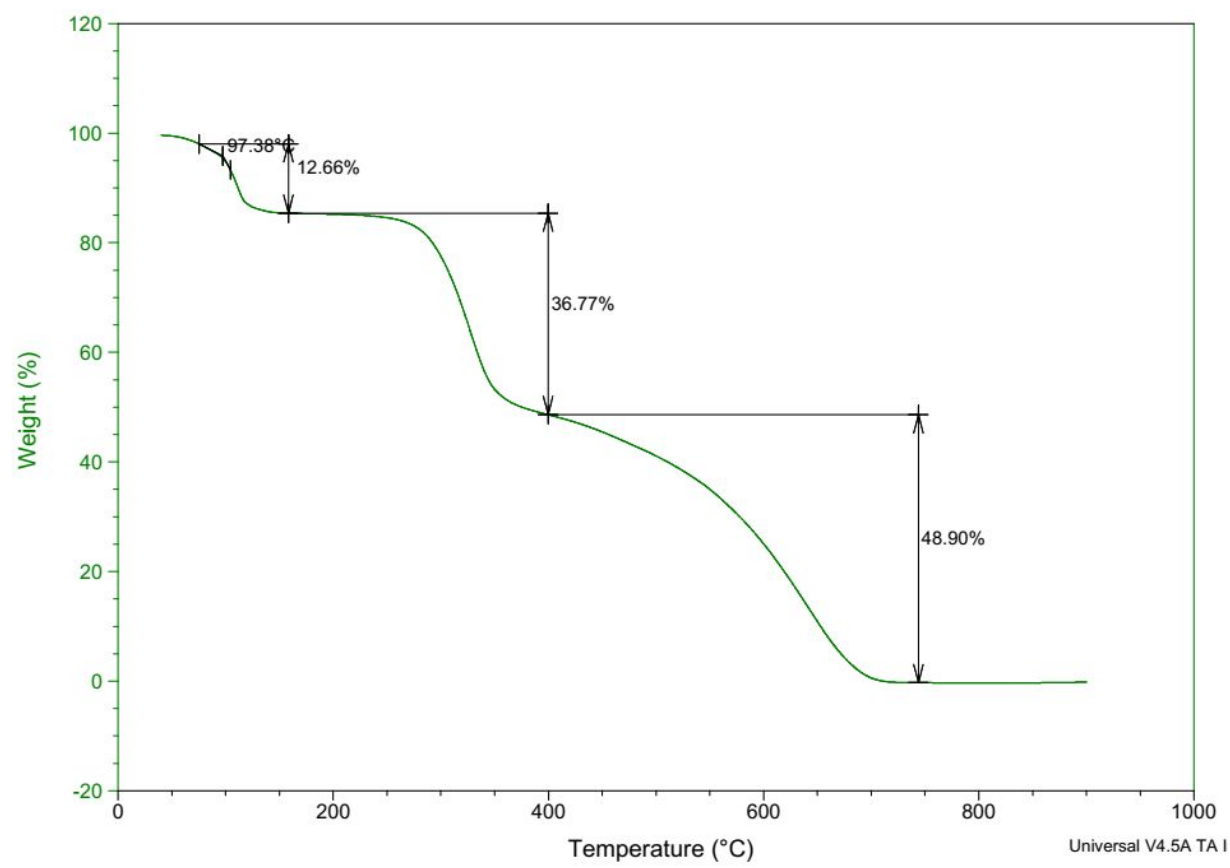

Figure S41. TGA thermogram of DBF•secBA $\supset \mathrm{H}_{2} \mathrm{O}$.

(1) Build 265

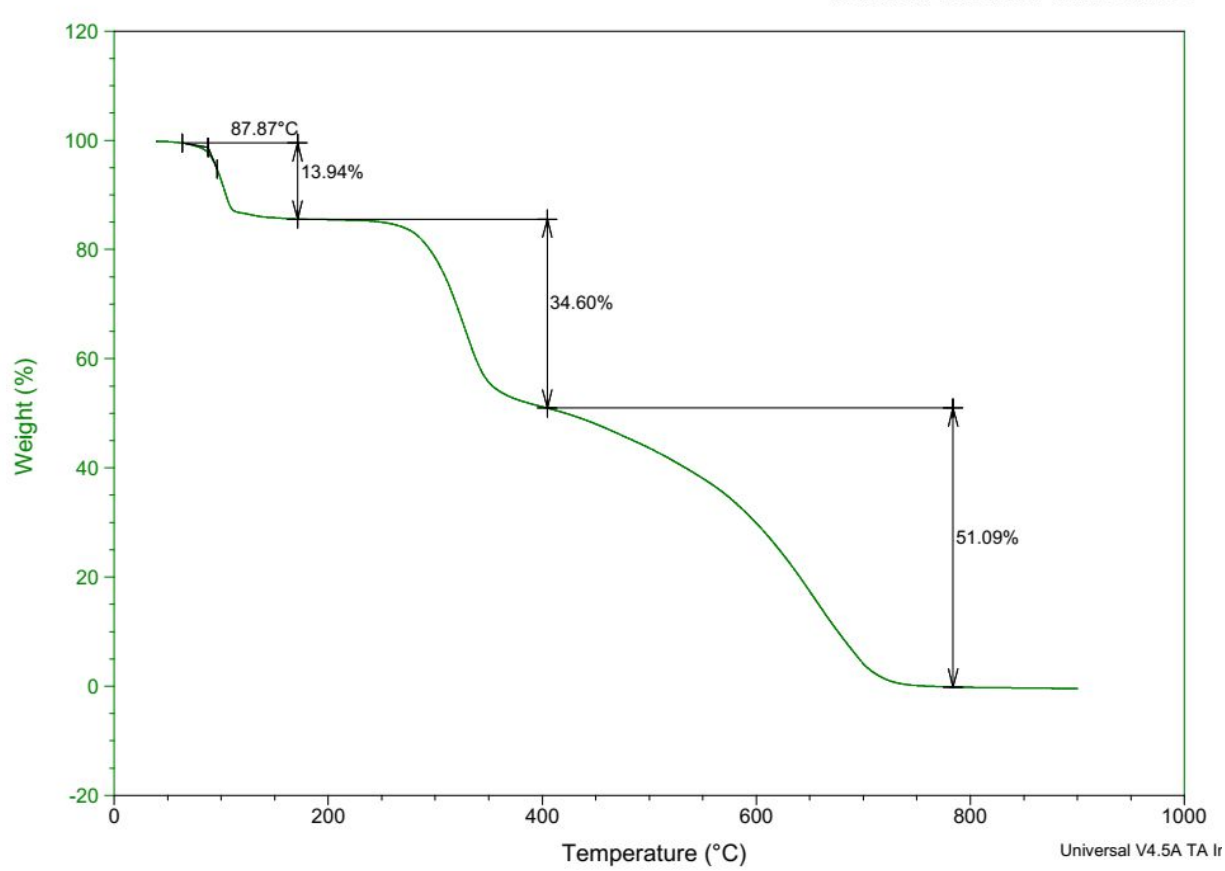

Figure S42. TGA thermogram of DBF•isoBA $\supset \mathrm{H}_{2} \mathbf{O}$. 


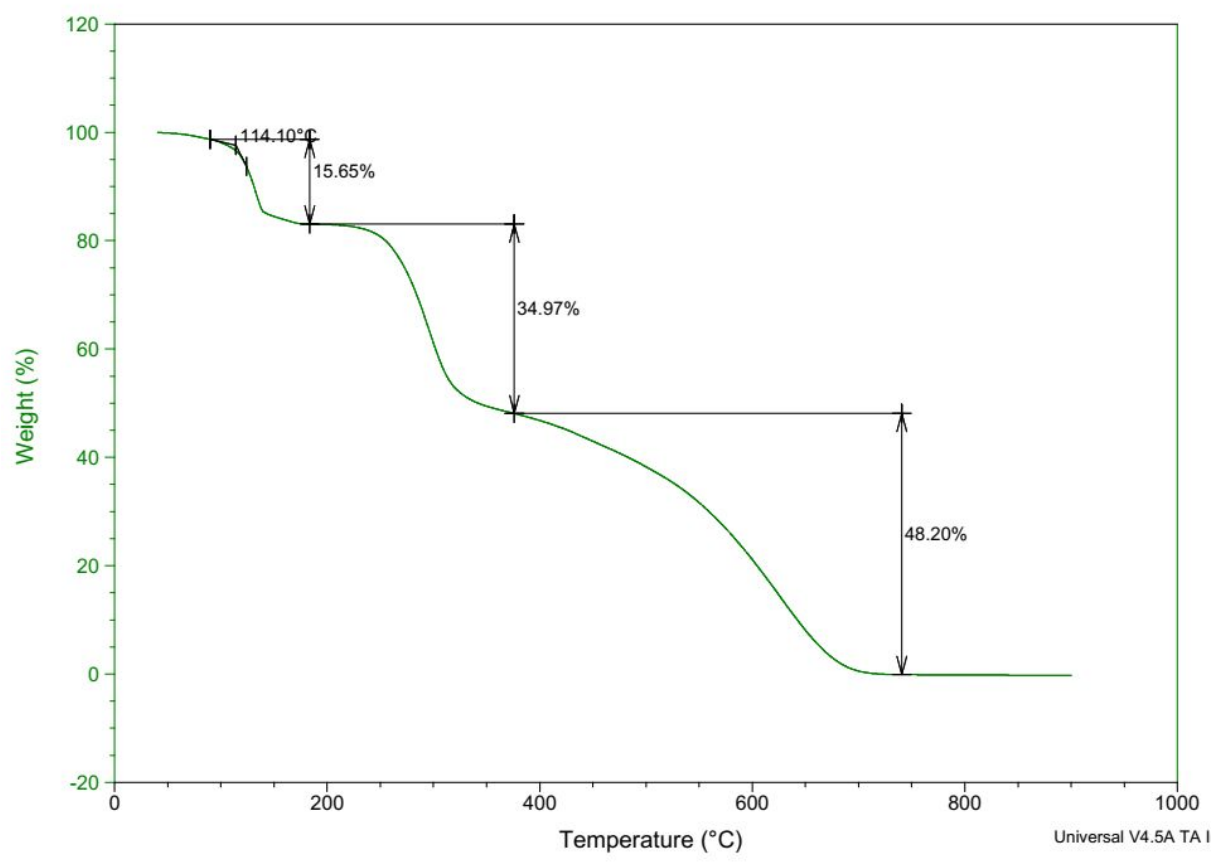

Figure S43. TGA thermogram of DBF•cycloHA $\supset \mathrm{H}_{2} \mathbf{O}$.

Run Date: 04-Sep-2018 11:42

Instrument: TGA Q5000 V3.17 Build 265

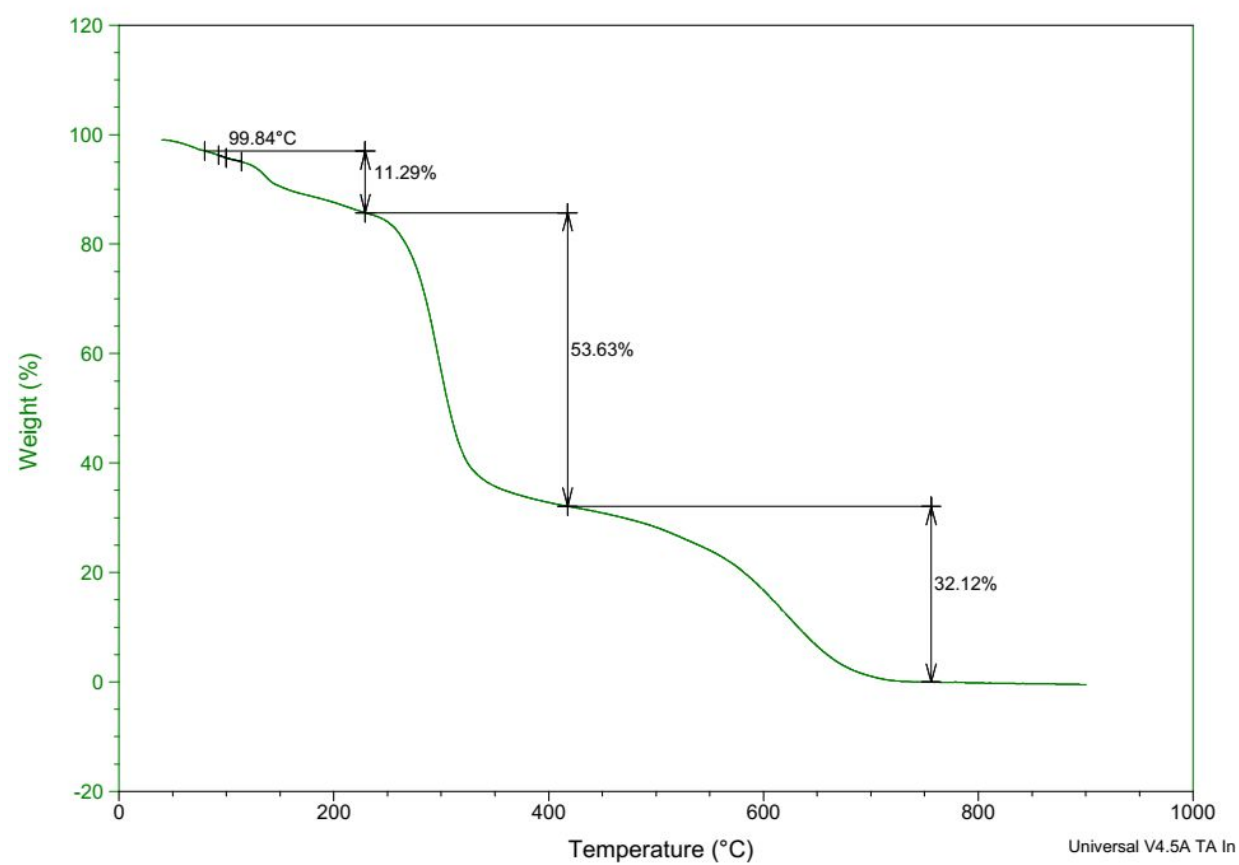

Figure S44. TGA thermogram of $\mathbf{D B F} \cdot \mathbf{E N} \supset \mathrm{H}_{2} \mathbf{O}$. 


\section{HPLC chromatogram of DBF}

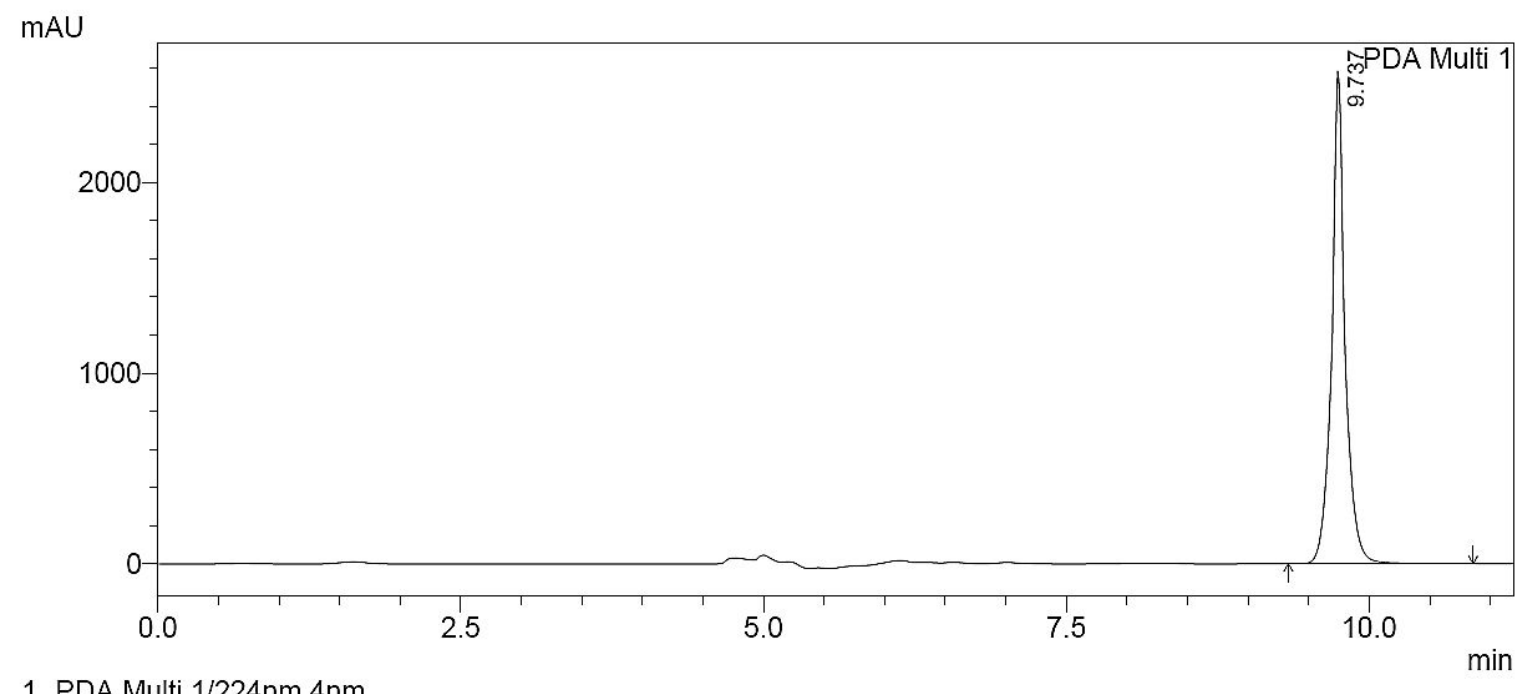

1 PDA Multi $1 / 224 \mathrm{~nm} 4 \mathrm{~nm}$

Figure S45. HPLC chromatogram of DBF with elution time at $9.73 \mathrm{~min}$ having absorbance at $224 \mathrm{~nm}$. 